\title{
Dielectric Elastomer Actuator for Soft Robotics Applications and Challenges
}

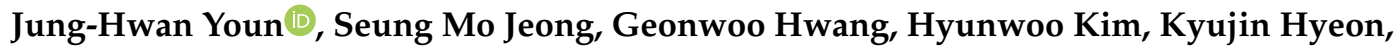 \\ Jihwan Park and Ki-Uk Kyung *
}

Department of Mechanical Engineering, Human-Robot Interaction Laboratory, Korea Advanced Institute of Science and Technology (KAIST), Daejeon 34141, Korea; jungwhan0810@kaist.ac.kr (J.-H.Y.); seungmoj@kaist.ac.kr (S.M.J.); geonwoo@kaist.ac.kr (G.H.); hyunwoo_kim@kaist.ac.kr (H.K.); axz0502@kaist.ac.kr (K.H.); wise4321@kaist.ac.kr (J.P.)

* Correspondence: kyungku@kaist.ac.kr; Tel.: +82-42-350-3245

Received: 16 November 2019; Accepted: 13 January 2020; Published: 16 January 2020

Featured Application: The main application area of dielectric elastomers is soft robotics as muscle-like actuators.

\begin{abstract}
This paper reviews state-of-the-art dielectric elastomer actuators (DEAs) and their future perspectives as soft actuators which have recently been considered as a key power generation component for soft robots. This paper begins with the introduction of the working principle of the dielectric elastomer actuators. Because the operation of DEA includes the physics of both mechanical viscoelastic properties and dielectric characteristics, we describe theoretical modeling methods for the DEA before introducing applications. In addition, the design of artificial muscles based on DEA is also introduced. This paper reviews four popular subjects for the application of DEA: soft robot hand, locomotion robots, wearable devices, and tunable optical components. Other potential applications and challenging issues are described in the conclusion.
\end{abstract}

Keywords: dielectric elastomer; principle; modeling; artificial muscle; soft robot

\section{Introduction}

With a recent robot design paradigm shift from conventional rigid body robots to soft robots with compliant bodies, in the area of soft actuators, electroactive polymers (EAPs) have been proposed as powerful materials for implementing a flexible actuation mechanism. As a type of EAP, dielectric elastomer works as a kind of actuator driven by the effective electrostriction between compliant electrodes and dielectric polymers [1]. Thanks to their light weight, flexibility with non-geometric constraints, cost-effectiveness, and fast response, dielectric elastomer actuators (DEAs) configured to various shapes are capable of enlarging their potentials to artificial muscle-like actuators [2]. So far, soft actuators, such as electroactive polymer actuators, shape memory alloy actuators, shape memory polymer actuators, and hydraulic or pneumatic actuators, etc., have opened many opportunities in artificial muscles, bioinspired robots, and user interfaces such as haptic or Braille devices [3].

This paper focuses on the review of potential capabilities and future perspectives of dielectric elastomer actuators for robotics applications. Each section includes historical background, current issues, and brief future perspectives of the subject. This review paper is composed of three main parts. Sections 1-4 introduce how a DEA works. Sections 5-7 are about robotic applications of the DEA. Sections 8 and 9 describe recent emerging applications, including soft-active optical lenses, biomedical applications, and others. 
Section 2 introduces the working principles and details of DEAs. This section introduces the essential elements for actuator design and their underlying physics. In Section 3, modeling of the dielectric elastomer is introduced. Due to its nonlinear behavior, the characteristics of DEAs have been found mostly from empirical studies rather than mathematical estimation [4-6]. In this section, recent modeling approaches and trends for the two representative actuator designs, circular plane and spring roll actuators, are introduced. As another introductory section, Section 4 describes design approaches for artificial muscle-like movement which includes contraction and expansion. Since a dielectric elastomer is usually found in the form of a thin film, fabricating a multiple layered structure guarantees a certain amount of thickness or length changes [7].

Thanks to the reconfigurability of elastomer, DEAs offer high potential to various applications such as robotic mechanisms, beyond artificial muscle itself. Section 5 deals with the design of DEAs based on robot hands which is a popular issue in soft robotics. It is expected that the soft feature of the robot hand based on DEAs enables the stable and gentle grasping of very brittle and soft objects. Section 6 describes the designing mobility of a DEA-based mechanism. This locomotive issue in soft robotics often mimics natures as a bioinspired design [8]. For another robotics application, we introduce a wearable interface design in Section 7 . We often see wearable robots for assisting kinesthetic movement or providing sensory cues like haptic feedback [9].

Section 8 introduces a new area. A soft actuator, which has the shape of a lens or is connected to a lens, can be used to vary focal length by itself for adaptive optical systems. The DEA embedded tunable lens is expected to contribute to the design of light-weight optical focal or zooming [10]. Sections 9 and 10 deal with other new applications and future challenging issues for the more practical use of DEAs which require very high driving voltage.

\section{Working Principle and Characteristics}

\subsection{Working Principle}

DEAs consist of a thin polymer film that is coated with compliant electrodes on both sides. When voltage difference is applied to the actuator, an electrostatic pressure is induced between the two electrodes, which then causes compression in its thickness direction. As dielectric elastomers are essentially incompressible, the compression causes an in-plane expansion, as shown in Figure 1.

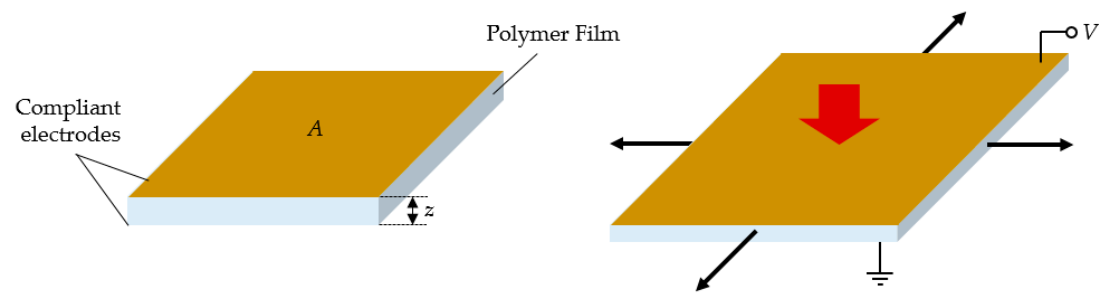

Figure 1. The dielectric elastomer (DE) operation principle by electrostatic forces.

DEA is essentially recognized as a compliant variable capacitor which converts the electrical energy to mechanical energy. The capacitance $C$ of the DEA can be expressed as

$$
C=\frac{\varepsilon_{0} \varepsilon A}{z}
$$

where $\varepsilon$ is the relative permittivity, $\varepsilon_{0}$ is the permittivity of free space, $A$ is the area of the compliant electrode, and $z$ is the thickness of the DE material. The stored electrical energy $U$ on the DEA with charge $Q$ is written as

$$
U=\frac{0.5 Q^{2}}{C}=\frac{0.5 z Q^{2}}{\varepsilon_{0} \varepsilon A}
$$


As noted above, DE material is essentially incompressible, which leads to the constant volume equation.

$$
A z=\text { Volume }=\text { constant }
$$

Then, the electrostatic pressure $p$, known as Maxwell stress, which acts across the two electrodes, can be derived.

$$
p=\varepsilon_{0} \varepsilon E^{2}=\varepsilon_{0} \varepsilon\left(\frac{V}{z}\right)^{2}
$$

where $E$ is the electric field and $V$ is the applied voltage. In the electrostatic pressure equation, DE material is assumed to have uniform thickness and uniform electrical charges on the surface. Using free boundary conditions and a linear elasticity assumption for small strains $(<10 \%)$, the thickness strain $s_{z}$ is given by [1].

$$
s_{z}=-\frac{p}{Y}=-\frac{\varepsilon_{0} \varepsilon E^{2}}{Y}=-\frac{\varepsilon_{0} \varepsilon}{Y}\left(\frac{V}{z}\right)^{2}
$$

where $Y$ is the elastic modulus. Since the polymers are assumed to be incompressible, a contraction in thickness results in a planar area expansion. As shown in the equation, the thickness strain is related to two mechanical parameters of the DE material: the elastic modulus $Y$, and relative permittivity $\varepsilon$. However, as these two parameters are functions of temperature, actuation frequency, and stress state, these variable terms should be dealt with to derive the dynamic behavior of the DEAs [2]. Furthermore, this model assumes that the material is linearly elastic, which is not suitable for most polymers. As polymers have a nonlinear and viscoelastic behavior, the viscoelastic model of a polymer should be considered to derive a more accurate equation. This is discussed in detail in Section 3.

Generally, DEAs are reported to have a large strain (>100\%), high efficiency, high energy density $\left(>3.4 \mathrm{MJ}^{-3}\right)$, and a fast response (in the order of milliseconds). The performance of DEAs is mainly determined by two factors, namely DE materials and compliant electrodes.

\subsection{DE Materials}

The selection of DE material is one of the key factors of DEAs. To enhance the performance of the DEA, the DE materials should have a low elastic modulus, low viscosity, high dielectric constant, and high electrical breakdown strength. Since many DE materials were tested, acrylic elastomers (3M VHB 4910 and VHB 4905), polyurethanes (PUs), and silicone elastomers are most commonly used. Using $3 \mathrm{M}$ VHB acrylic elastomer as a DE has benefits in generating a large strain. DEA using 3M VHB acrylic elastomer with large pre-strain shows the strain over 380\% [3]. Recently, various silicone elastomers, such as Dow Corning Sylgard 186, Dow Corning HS3, Nusil CF19-2186, Wacker Elastosil RT 625, Wacker Elastosil P7670, THERABAND YELLOW 11726, and OPPO BAND GREEN 8003 were tested as DE materials [11,12]. Compared to the acrylic elastomers, silicone elastomers have relatively low DE constants, and thereby require higher electrical fields to achieve high strain. However, as acrylic elastomers have a higher viscosity than silicone elastomers, the silicone elastomers are more suitable in the applications operating at higher frequencies [4].

The pre-strain of the DE materials is also an important factor to improve the actuation performance. Pre-strain can improve breakdown strength [5] and mechanical stability but can also cause a decrease in the DE constant [6]. Table 1 compared the properties of DEAs of various DE materials and other actuators.

Table 1. Comparison of the properties of actuators.

\begin{tabular}{cccccc}
\hline References & Type & Pre-Strain (x, y) (\%) & Maximum Strain (\%) & $\begin{array}{c}\text { Work Density per } \\
\text { Cycle (J/cm } \mathbf{s}^{\mathbf{3}} \text { ) }\end{array}$ & $\begin{array}{c}\text { Maximum Energy } \\
\text { Efficiency }\end{array}$ \\
\hline$[13-15]$ & Dielectric elastomer (VHB 4910) & 300,300 & 158 (Circular area strain) & $<3.4(0.15$ typical) & $80(30$ typical) \\
{$[13-15]$} & Dielectric elastomer (VHB 4910) & 540,75 & 215 (Linear area strain) & $<1.36$ & $80(30$ typical) \\
{$[16,17]$} & Dielectric elastomer (polyurethane acrylate) & 0,0 & 66.7 (Circular area strain) & 0.087 & 80 \\
{$[17]$} & Dielectric elastomer (Sylgard 186) & 0,0 & 32 (Circular area strain) & 0.082 & 90 \\
{$[3,14]$} & Dielectric elastomer (CF19-2186) & 45,45 & 64 (Circular area strain) & 0.75 & 79 \\
\hline
\end{tabular}


Table 1. Cont.

\begin{tabular}{|c|c|c|c|c|c|}
\hline References & Type & Pre-Strain $(x, y)(\%)$ & Maximum Strain (\%) & $\begin{array}{c}\text { Work Density per } \\
\text { Cycle }\left(\mathrm{J} / \mathrm{cm}^{3}\right)\end{array}$ & $\begin{array}{l}\text { Maximum Energy } \\
\text { Efficiency }\end{array}$ \\
\hline [14] & Dielectric elastomer (CF19-2186) & 100,0 & 63 (Linear area strain) & 0.2 & - \\
\hline [14] & Dielectric elastomer (HS3) & 280,0 & 117 (Linear area strain) & 0.16 & - \\
\hline$[3,18]$ & Shape memory alloy wire (NiTi) & - & $6-8$ & 100 & $3 \sim 10$ \\
\hline$[19,20]$ & Shape memory alloy coil spring (NiTi) & - & 300 & $>100$ & $3 \sim 10$ \\
\hline [3] & Shape memory polymer (polyurethane) & - & $100-400$ & 2 & 10 \\
\hline [3] & Piezoelectric ceramic (PZT) & - & 0.2 & 0.1 & 90 \\
\hline [3] & Piezoelectric polymer (PVDF) & - & 0.1 & 0.0024 & - \\
\hline [3] & Conductive polymer (PANI) & - & 10 & 23 & $<5$ \\
\hline [3] & Ionic gel (polyelectrolyte) & - & 40 & 0.06 & 30 \\
\hline [21] & PVC gel actuator & - & 76 & - & - \\
\hline [22] & Coiled actuator (Nylon) & - & 50 & 0.84 & - \\
\hline$[15,18]$ & Natural human muscle & - & 40 & $0.008 \sim 0.04$ & $35-40$ \\
\hline
\end{tabular}

\subsection{Compliant Electrodes}

Compliant electrodes are also an important factor to achieve the enhanced performance of DEAs, as well as DE materials. To be used in DEAs, the compliant electrodes should have high conductivity, strong adhesion to most DE materials, good stability, and be highly compliant. As of now, the most commonly used compliant electrodes are carbon grease, carbon black, and graphite $[23,24]$. These electrodes are cheap, have high conductivity, and are easy to use. However, they have an instability problem in the case of long-term use as carbon black and graphite can be detached from the DE materials, and oil in carbon grease can become dry. Recently, silver nanowires (AgNWs) and single-walled carbon nanotubes (SWCNTs) have become promising transparent compliant electrodes for DEAs as they have high stretchability and conductivity while remaining highly transparent $[25,26]$. Ionic conductors are also considered promising candidates as transparent compliant electrodes for DEAs. It has been reported that ionic conductors have lower resistance than other transparent electronic conductors, such as AgNWs or SWCNTs, at large deformation [27]. Figure 2 compares the properties of compliant electrodes of DEAs.

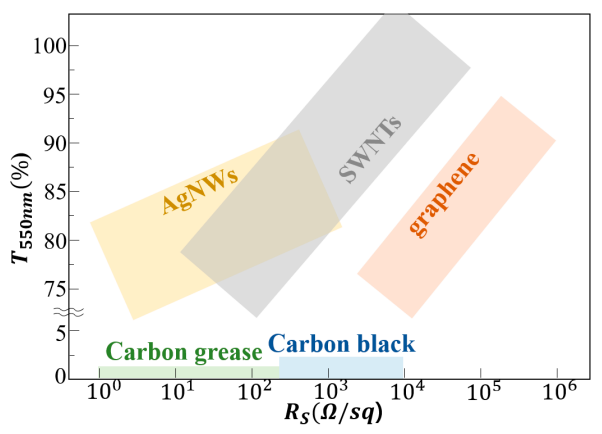

Figure 2. Comparison of the transmittance and sheet resistance of compliant electrodes.

\section{Modeling of DEA}

As introduced in the previous section, DEs are recognized for their large planar strain. To incorporate this expanding nature into an actuator, various actuator configurations were designed, such as spherical, stack, bending, and rolled actuators [7,28]. However, in order to operate DEAs to their full potential under various conditions, a fundamental understanding of their working principle is essential. The first step in modeling DEAs was taken by Pelrine and Kornbluh. They revealed that electromechanical transduction effects in DEs are due to the Maxwell stress $[1,23,29]$. While the working principle may seem simple, an accurate modeling of DEAs still proves to be a challenge.

In order to overcome such a challenge, many researchers proposed DE actuation models based on nonequilibrium thermodynamics of the material. Such thermodynamics of DEs were reviewed by Suo and colleagues [30,31]. Taking the planar expansion in Figure $3 a, b$ as an example, in the reference state, the DE film is of the dimensions $\mathrm{L}_{1}, \mathrm{~L}_{2}$, and $\mathrm{L}_{3}$. In the current state, the DE film is of dimensions $l_{1}, l_{2}$, 
and $l_{3}$, and subject to forces $P_{1}, P_{2}$, and $P_{3}$, and to voltage $\Phi$. When the DE film reaches equilibrium with the forces and the voltage, the change in the free energy equals the work done on the film:

$$
\delta \mathrm{F}=P_{1} \delta l_{1}+P_{2} \delta l_{2}+P_{3} \delta l_{3}+\Phi \delta Q
$$

where $F$ is the Helmholtz free energy of the film, while $Q$ is the electric charge accumulated on the film and is related to electric displacement by $Q=D l_{1} l_{2}$.

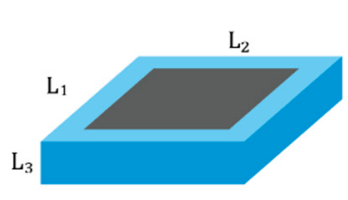

(a)

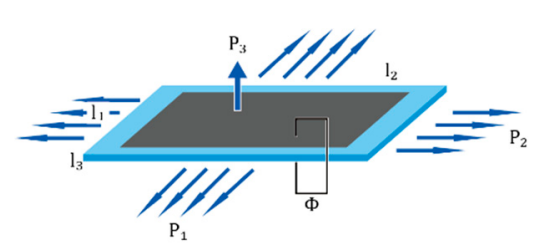

(b)

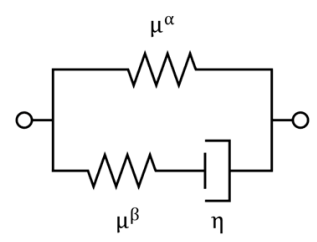

(c)

Figure 3. DE actuation schematic. (a) Reference state; (b) Current state; (c) Rheological model.

Defining the nominal density of the Helmholtz free energy by $\mathrm{W}=\mathrm{F} /\left(\mathrm{L}_{1} \mathrm{~L}_{2} \mathrm{~L}_{3}\right)$, the stretches by $\lambda_{1}$ $=l_{1} / \mathrm{L}_{1}, \lambda_{2}=l_{2} / \mathrm{L}_{2}$, and $\lambda_{3}=l_{3} / \mathrm{L}_{3}$, and assuming the incompressibility of the material as $\lambda_{1} \lambda_{2} \lambda_{3}=1$, and the electric field as $\mathrm{E}=D / \varepsilon$, where $\varepsilon$ is the permittivity of the film, the following relationship is obtained:

$$
\mathrm{W}\left(\lambda_{1}, \lambda_{2}, D\right)=\mathrm{W}_{\mathrm{s}}\left(\lambda_{1}, \lambda_{2}\right)+\frac{D^{2}}{2 \varepsilon}
$$

The first term on the right-hand side of the equation is the Helmholtz free energy associated with the stretching of the elastomer, and the second term represents the electrostatic energy of the film [9,32].

Early works modeled the strain energy, $\mathrm{W}_{\mathrm{s}}$, with elastic material models. However, elastic material models alone are insufficient to model the DE's strain behavior correctly. This is because DEs have nonlinear material properties and undergo time-dependent dissipative processes, such as viscoelastic, dielectric, and conductive relaxations [28,30]. To overcome this limitation, many researchers have proposed various methods to model the viscoelastic behavior of DEs, such as the Prony series or rheological models [28]. The viscoelastic material model that is being frequently used is the three-parameter rheological model shown in Figure 3c. The three-parameter solid model is composed of springs, each with their own shear modulus, $\mu^{\alpha}$ and $\mu^{\beta}$, and a damper with a coefficient of viscosity, $\eta$. Here, the sum of two spring shear moduli is the shear modulus of the material $[32,33]$. Recent works utilize hyperelastic material models, such as the Gent, the Neo-Hookean, or the Yeoh model with the rheological model to predict the DEA's behavior [28,34-36].

As mentioned, there are various configurations for DEAs. As stated by Kornbluh, these actuators can be roughly categorized into two groups depending on their morphology. One group of actuators utilizes basic in-plane expansion, such as circular (diaphragm), extender, and bending beam actuators. Another group exploits the desirable features of elastomers such as the monolithic structure, flexibility, and multifunctionality. Examples of this group are spring roll actuator, bow actuator, and spider actuation [7]. To outline the modeling trend for DEAs, one actuator from each category has been selected. Their modeling trend is listed in Table 2, and their configurations are represented in Figure 4 . The actuator shown in Figure 4a,b is a circular planar actuator. It is composed of a single DE film and a pair of concentric circular electrodes placed on the top and bottom of the film. Upon voltage activation, the coated part of the actuator undergoes in-plane expansion. 
Table 2. Modeling trend of dielectric elastomer actuators (DEAs).

\begin{tabular}{|c|c|c|c|c|c|c|c|c|c|}
\hline Year, Config. & Electrode & Modeling Method & Material Model & Viscoelastic Model & $\begin{array}{c}\text { Static/Dynamic } \\
\text { Analysis }\end{array}$ & Strain Rate & Pre-Stretch & Sim & Exp. ${ }^{1}$ \\
\hline 2005, Circular [37] & Beaten gold & Numerical & Yeoh & Prony series & Static & No & No & Yes & Yes \\
\hline 2006, Circular [5] & Hydrogel & Numerical & $\begin{array}{l}\text { Ogden } \\
\text { Yeoh, }\end{array}$ & Rheological model & Static & Yes & Yes & Yes & Yes \\
\hline 2007, Circular [38] & Graphite/Silicone & Numerical & $\begin{array}{c}\text { Arruda-Boyce, } \\
\text { Ogden }\end{array}$ & - & Static & No & Yes & Yes & Yes \\
\hline 2011, Circular [39] & Carbon grease & Analytical & Gent, Neo-Hookean & - & Static & No & Yes & Yes & Yes \\
\hline 2012, Circular [40] & - & Analytical & Gent & Rheological model & Both & Yes & Yes & Yes & No \\
\hline 2014, Circular [41] & Carbon grease & Analytical & Gent & Rheological model & Static & Yes & Yes & Yes & Yes \\
\hline 2018, Circular [28] & Carbon grease & Analytical & Gent & Rheological model & Both & Yes & Yes & Yes & Yes \\
\hline 2019, Circular [34] & Carbon grease & Analytical & Gent & Rheological model & Static & Yes & Yes & Yes & No \\
\hline 2006, Spring Roll [42] & - & Analytical & - & - & Static & No & Yes & Yes & Yes \\
\hline 2006, Spring Roll [43] & - & Numerical & - & - & Static & No & Yes & Yes & Yes \\
\hline 2007, Spring Roll [44] & - & Numerical & Yeoh & - & Static & No & Yes & Yes & No \\
\hline 2008, Spring Roll [45] & - & Analytical & Gaussian & - & Static & No & Yes & Yes & No \\
\hline 2008, Spring Roll [46] & Carbon grease & Numerical & - & - & Static & No & Yes & Yes & Yes \\
\hline 2015, Spring Roll [35] & Carbon grease & Analytical & Neo-Hookean & Rheological model & Both & Yes & No & Yes & No \\
\hline 2016, Spring Roll [36] & Carbon grease & Numerical & Yeoh & - & Static & No & No & Yes & Yes \\
\hline
\end{tabular}

${ }^{1}$ Criteria for checking whether formulated model has been verified experimentally. 


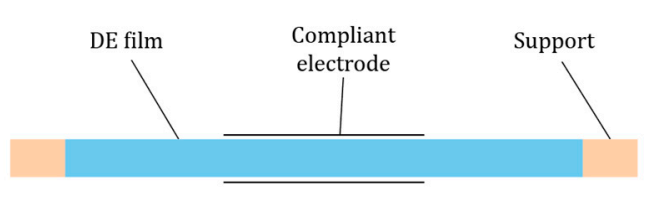

(a)

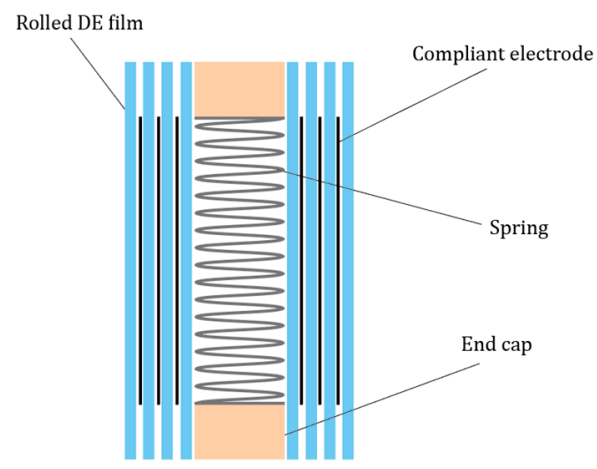

(c)

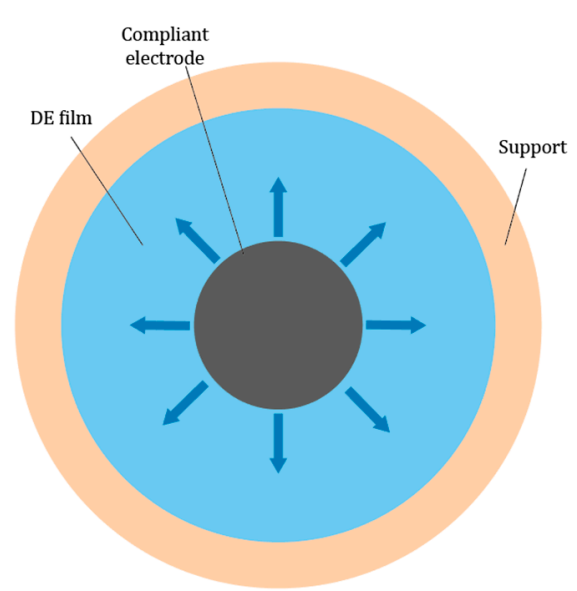

(b)

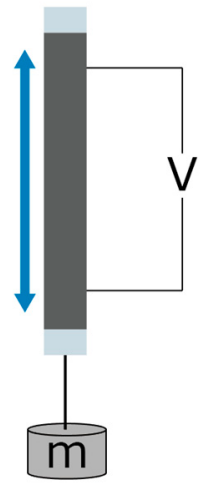

(d)

Figure 4. DE actuator configurations: (a) Structure of a circular actuator; (b) Electrically activated circular actuator; (c) Internal structure of a spring roll actuator; (d) Electrically activated spring roll actuator with a hanging mass.

In the top half of Table 2, the modeling trend for the circular DEA is shown. There are two main branches in the modeling method. One is modeling with a numerical model, such as the finite element model, and the other is with an analytical model, such as the non-equilibrium thermodynamic model. In the 2000s, the viscoelasticity of the DE was either neglected or modeled with the Prony series. After the research on the non-equilibrium Helmholtz free energy analysis, a combination of the Gent material model and the rheological viscoelastic model became the standard in the corresponding modeling branch. Yet, DE behavior analysis is still focused more on its static actuation than dynamic actuation.

The actuator in Figure $4 \mathrm{c}, \mathrm{d}$ is a spring roll DEA. This actuator is also composed of DE films. It is fabricated by wrapping DE film around a spring core. The DE film may be pre-stretched and the spring may be compressed before wrapping. As a result, upon voltage activation, the planar expansion of the DE film is converted into linear movement in the axial direction. The bottom half of Table 2 shows the trend for a spring roll type DEA. Unlike the circular actuator, there are fewer attempts in modeling and analyzing the spring roll actuator with a viscoelastic model. This is most likely due to the greater complexity in fabrication and modeling. Nevertheless, the modeling of the spring roll actuator shows a similar trend to that of the circular actuator. The spring roll actuator is also being modeled through the analytical model using the neo-Hookean and the rheological model, or through the numerical model.

In recent years, attention to DEA's dynamic actuation has grown. Several experiments have observed and reported the time-dependent behavior of DEAs due to their viscoelastic effect [47-53]. Cyclic loading simulations and experiments reveal a distinct temporal evolution behavior, which can be characterized by transient and stable regions. As mentioned previously, to model a DEA's viscoelastic behavior, methods such as using the Prony series or the three-parameter solid model were attempted. 
These methods may be adequate in modeling static behavior. However, they fail to accurately model and follow a DEA's cyclic loading behavior. To solve this issue, several modeling methods were proposed. The rheological model shown in Figure $2 c$ has one elastic spring module in parallel with one viscoelastic module, composed of a spring and a dashpot. In 2017, Gu et al. introduced an extended rheological model. This model consists of one elastic module in parallel with multiple viscoelastic modules. Forming the general model with the Gent model to describe the strain stiffening effect, it was experimentally validated that increasing the number of viscoelastic modules in the rheological model increases the model's prediction accuracy when describing a DEA's response [47].

Another method of describing a DEA's time-dependent behavior was proposed by Zhang et al. In this paper, to describe both the viscoelastic creep and relaxation, a Kelvin-Voigt-Maxwell (KVM) model was proposed. From the paper, it was experimentally shown that the KVM model is more accurate in capturing a DE's initial rapid creeping behavior upon step voltage input [48]. However, long-term relaxation behavior prediction performs similarly to the three-parameter model. In 2018, the viscoelastic modeling approach using phenomenological models was introduced by Zou and Gu. The paper proposed a modified rate-dependent Prandtl-Ishlinkii model (MRPIM) that can describe the asymmetric viscoelastic hysteresis effect with a maximum error of $9.03 \%$ [49]. Previously described modeling methods, based on the rheology of the elastomer, require a thorough understanding of the actuator. In contrast, phenomenological approaches are advantageous in that only experimental data are required to characterize a DEA's complex viscoelastic behavior.

As a DE's nonlinearity and time-dependent behavior are being analyzed and understood, methods of controlling such nonlinear actuators are being studied as well. In 2019, a high-precision control method using inverse viscoelastic hysteresis compensation was proposed [50,51]. Authors used a feedforward inverse hysteresis controller with a phenomenological hysteresis model to compensate for the DEA's hysteresis, and combined it with a classical proportional-integral feedback controller to compensate for the creeping behavior. Experiments were performed with conical out-of-plane DEAs, and results show a high-precision control with a maximum tracking error of 3.95\% [51]. Along with a closed-loop control method, a comparatively simple open-loop control of DEAs was proposed by Rosset and his colleagues. In this approach, the open-loop control law is devised using quasi-linear viscoelasticity. For the material model, a series of Kelvin-Voigt elements are used. Experimental results show that, even without an additional self-sensing mechanism, the actuator follows the target strain with a small tracking error [52].

While modeling DE's nonlinearity and consequently controlling DEAs are of great importance, investigating an actuator's usability is also as important. To apply a DEA outside of a laboratory, the study on instabilities and allowable actuation states is crucial. Fundamental studies analyzing DE instabilities and mapping an actuator's failure modes have been initiated. For the case of spring roll DEAs, electromechanical instability, electrical breakdown, tension loss, tensile rupture, and compressive limit were defined, and their relationship and effects on performance and design were investigated [31,46]. Recently, the electromechanical instability of a DE balloon was studied as well [54]. Still, the study can be further developed by experimentally verifying the impact of such failure modes on the actuator. Overall, there has been a great development in DE modeling since the first one-dimensional model by Perline and Kornbluh. Yet, it cannot be concluded that a DE's actuation behavior is completely clarified and defined. Thus, for the practical application of DEAs, more attention and research on modeling is required.

\section{Artificial Muscle Design and Fabrication}

Artificial muscle is an actuator that can produce mechanical movements similar to natural muscles, through electromagnetic, thermal, or chemical energy. Natural muscle can lift or support heavy objects by generating up to $80 \mathrm{Ncm}^{-2}$ force and $200 \%$ strain, and a $250-\mathrm{Hz}$ strain rate allows for a fast response to external stimuli [55]. In addition, it has high controllability and is composed of soft tissues, so it can move precisely and absorb shock. Artificial muscle technologies have been approached in various ways 
to simulate the high performance of natural muscle. Among them, DEAs are attracting attention as next-generation artificial muscle technology, because they can produce large mechanical deformation, have fast response speed, and are soft, as summarized in Table 1.

Natural muscle is a linear actuator that can produce great force and strain. A DEA, however, has an exertion stress limit, because of the breakdown and saturation of the electric field [8]. In order to improve this problem, related researches are being conducted to increase strain and force by using a multi-layer configuration. Also, as a DEA basically operates by areal expansion, various configurations are proposed to create linear movement. Configurations can be classified into a contraction type, which uses DE material thickness reduction, and an expansion type, which uses area increase. Currently, artificial muscle like DEAs are being developed to improve its performance, by designing new configurations or optimizing design parameters of existing configurations.

\subsection{Linear Contraction DEA}

A multi-stack actuator is fabricated by stacking multiple electrodes and elastomers in order to increase the Maxwell stress, and consequently its performance. A multi-stack actuator is shown in Figure $5 \mathrm{a}$. It has been reported that over $100 \%$ of strain is obtained by the actuation of more than 100 layers using this configuration. The frequency response test confirmed that it has a resonant frequency at about $200 \mathrm{~Hz}[56,57]$. In addition, an actuator with a maximum strain of up to $-10 \%$ at $4.1 \mathrm{kV}$ that can withstand $20.74 \mathrm{~N}$ has been studied through the development of an optimized design and fabrication process [58,59]. On the other hand, as the number of layers increase, fabrication becomes more difficult. To solve this problem, a configuration of folding one DEA in half, so that the effect of two layers can be achieved with one electrode pair was proposed [60-62]. This actuator can create a strain of $-7.5 \%$ at a maximum of $3.5 \mathrm{kV}$ under compressive stress with a $100 \mathrm{~g}$ load. Currently, a remarkable strain of up to $24 \%$ was achieved by using a UV curable acrylic elastomer [63]. Moreover, a commercially available multi-stack actuator has come into the market [64]. This actuator produces 3.3\% of strain at $1.2 \mathrm{kV}$ and has low power consumption as well as a high life cycle. Another fabrication method that simplifies the process with monolithic fabrication was proposed as well. Helical and folded monolithic actuator configurations are described below.
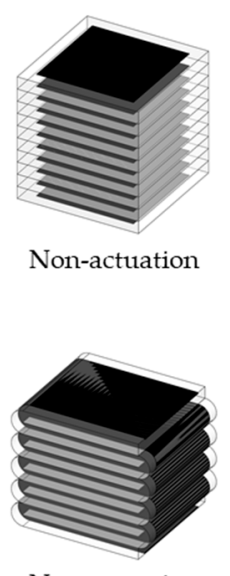

Non-actuation

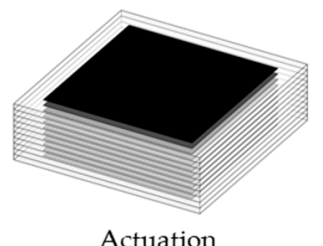

(a)

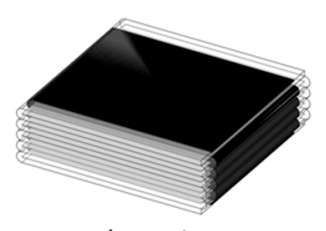

Actuation

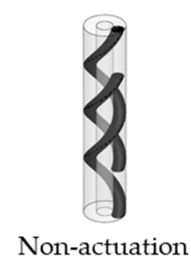

Non-actuation

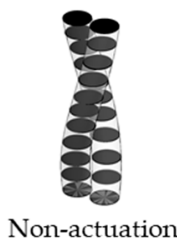

(b)

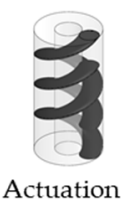

Actuation

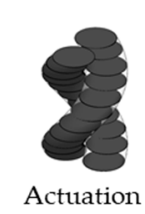

(d)

(c)

Figure 5. Schematics of Linear Contraction DEA. Transparent: Elastomers, Black: Electrodes (a) Multi-stack actuator; (b) Helical actuator; (c) Folded actuator; (d) Twisted actuator.

A helical actuator is a structure in which a compliant electrode is inserted between two identical pitch helical elastomers. The electrode pair in the axial direction expands in the radial direction due to the Maxwell stress, creating a contraction strain in the axial direction as shown in Figure 5b. A helical

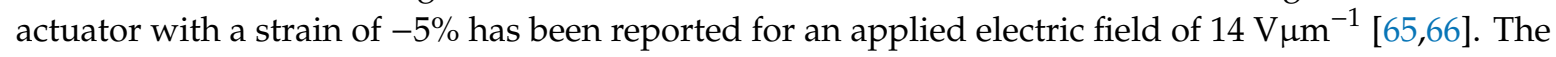


helical actuator configuration can reduce fabrication time more than a multi-stack actuator configuration because of the reduced number of elastomers. However, a limit to elastomer thickness exists due to the blade fabrication method.

A folded actuator is similar to multi-stack actuator, but the complexity and time of fabrication is reduced efficiently by folding a single long DEA multiple times, as shown in Figure $5 \mathrm{c}$. A rectangular folded actuator with a contraction strain of $-16 \%$ is reported for an applied electric field of 12

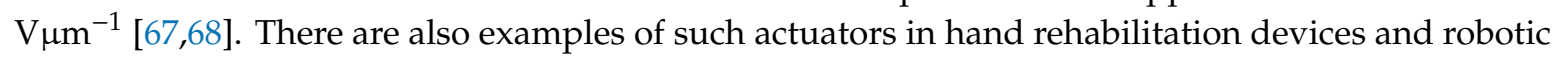
eyeball moving equipment [69].

Besides helical and folded actuator configurations, there is a twisted actuator, which is modified from a multi-stack actuator, as shown in Figure 5d. This configuration is made by twisting two cylindrical multi-stack actuators. The two spiral actuators contract to create strain as the helix angle changes. This actuator configuration solves the vulnerability issue of the multi-stack actuator. The twisted actuator is more stable to external force. An actuator with a maximum of $13.7 \mathrm{Wkg}^{-1}$ of specific power with a $300 \mathrm{~g}$ load and $-5.2 \%$ contraction strain without load has been reported [70].

\subsection{Linear Expansion DEA}

A cone actuator is a configuration in which DE material is inserted inside of a rigid frame and extended by pre-loading, as shown in Figure 6a. When the Maxwell stress is applied to the DE material, the stroke occurs in the direction of pre-loading by areal expansion. This actuator has the advantage of a relatively large energy density compared to other configurations because the pre-loading energy can be used. Cone actuators can be classified into single-cone actuators and double-cone actuators according to their shape. For the single-cone actuator, pre-loading can be applied by a hanging mass or using a compressed spring in the center. In the case of a hanging mass, a single-cone actuator composed of two layers of VHB 4910 acrylic elastomer and a mass of $200 \mathrm{~g}$ was reported to have a stroke of about $7 \mathrm{~mm}$ and an output force of $1.7 \mathrm{~N}$ [71,72]. Also, a $86 \times 86 \times 25 \mathrm{~mm}$ sized spring single-cone actuator made of $50 \mu \mathrm{m}$ Elastosil had outstanding lifting performance, lifting $10 \mathrm{~kg}$ by $3 \mathrm{~mm}$ [73]. A double-cone actuator is composed of two antagonistic cone actuators and connected with a strut or magnetic repulsion in the center. The strut double-cone actuator is capable of vertical strokes as well as rotation and lateral strokes. Using a strut double-cone actuator made of VHB 4910, a maximum of $49.5^{\circ}$ rotational stroke, $8.1 \mathrm{~mm}$ lateral stroke, and $11.3 \mathrm{~mm}$ vertical stroke were produced at $3 \mathrm{kV}[74,75]$. Using this approach, up to six degrees of freedom can be achieved by patterning the electrodes [76] and eyeball movement devices were made by applying this advantage [77]. Recently, a method of using magnets instead of struts inside a double-cone actuator has been proposed. The magnetic double-cone actuator uses the principle that the stroke occurs up to the point where the magnetic repulsion force and the reaction force of the DE material are balancing. A maximum of 4.06 $\mathrm{mm}$ stroke at $60 \mathrm{~V} \mu \mathrm{m}^{-1}$ electric field was reported by using $100 \mu \mathrm{m}$ Elastosil [78].

A tubular actuator consists of a DE tube with its insides and outsides covered with compliant electrodes as shown in Figure $6 \mathrm{~b}$. By contracting in the radial direction, the actuator performs linear

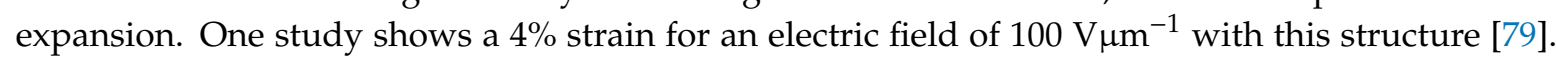
A tubular actuator consists of one layer in the radial direction, making it difficult to obtain high Maxwell stress. Therefore, an actuator with multiple layers is suggested to increase the force and strain. In addition, various tubular actuators with substructures have been fabricated. Additional structures were used to maintain the pre-strain of DE material, and to improve the performance. The representative examples are the tubular actuator with a compressed spring in the core, generating up to $14 \%$ strain in $7.5 \mathrm{kV}$ [42].

A roll actuator is made by rolling a single long layer which has the effect of superposing Maxwell stress, like multi-stack actuators, for the same working voltage. The roll actuator is represented in Figure $6 \mathrm{c}$. It is reported that more than $10 \%$ of strain was obtained with the basic configuration of the roll actuator [1]. Moreover, 2-DOF and 3-DOF roll actuators capable of bending or rotation as well as axial expansion motion were proposed by patterning two or four electrodes in the circumferential 
direction [80]. The roll actuator is mostly used as an artificial muscle among DE actuators. Currently, the theoretical and failure modeling of roll actuators has been conducted mostly to investigate and optimize performance $[35,36,80]$. Like the tubular actuator, the spring roll actuator has been reported by inserting a compressed spring in the core, and it shows a maximum $35 \%$ strain [44]. In addition, an interpenetrating polymer network that can compensate the residual stress of pre-strain has shown a $10 \%$ performance at $6 \mathrm{kV}$ without a compressed spring [81]. Recently, many researches have reported using fiber to enhance performance. The shorter the roll actuator, the greater the actuation tends to be. So, the fiber roll actuator was suggested to produce up to $35.8 \%$ strain at $21 \mathrm{kV}$, independent of its aspect ratio, by arranging the fiber in the circumferential direction [82]. Furthermore, applying internal pneumatic pressure to prevent buckling of the fiber due to excessive pre-strain has been reported [83]. The maximum performance of each configuration are arranged in Table 3.

However, uneven thickness, non-uniform electric field, and stress concentration limit the performance of DEA. By adopting appropriate manufacturing approaches, such as microfabrication, the dielectric elastomer membrane's quality and uniformity can be improved, and consequently increase its performance.

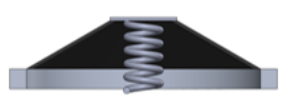

Non-actuation

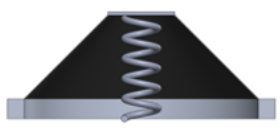

Actuation

(a)

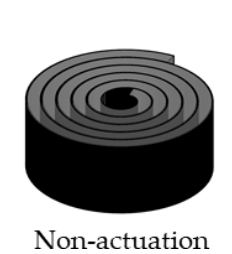

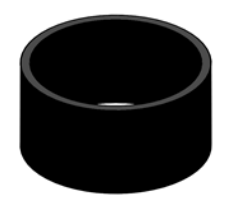

Non-actuation

(b)

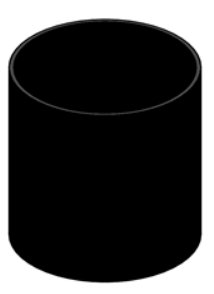

Actuation

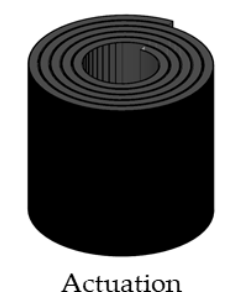

(c)

Figure 6. Schematics of Linear Expansion DEA. Transparent: Elastomers, Black: Electrodes (a) Cone actuator; (b) Tubular actuator; (c) Roll actuator.

Table 3. Maximum performance of DE artificial muscle design.

\begin{tabular}{|c|c|c|c|c|c|c|c|}
\hline Configurations & Nominal Electric Field & Pre-Strain & Material & Size & Load $^{1}$ & Strain or Stroke & Ref. \\
\hline \multicolumn{8}{|c|}{ Linear Contraction } \\
\hline Multi-stack & $4.2 \mathrm{kV} / 40 \mu \mathrm{m}$ & $400 \%$ biaxial & VHB $4910+$ IPN & $18 \times 18 \times 18.3 \mathrm{~mm}^{3}$ & $20.74 \mathrm{~N}$ & $-10 \%$ & [58] \\
\hline Helical & $14 \mathrm{~V} / \mu \mathrm{m}$ & None & TC-5005 & $13 \times 13 \times 80 \mathrm{~mm}^{3}$ & None & $-5 \%$ & [65] \\
\hline Folded & $12 \mathrm{~V} / \mu \mathrm{m}$ & None & TC-5005 & $25 \times 25 \times 85 \mathrm{~mm}^{3}$ & None & $-15 \%$ & [68] \\
\hline Twisted & $6.5 \mathrm{kV} / 220 \mu \mathrm{m}$ & None & $\begin{array}{c}\text { Elastosil P7670 + } \\
\text { PT88 }\end{array}$ & $11.5 \times 11.5 \times 80 \mathrm{~mm}^{3}$ & $100 \mathrm{~g}$ & $-5.2 \%$ & [70] \\
\hline \multicolumn{8}{|c|}{ Linear Expansion } \\
\hline Cone & $90 \mathrm{~V} / \mu \mathrm{m}$ & $20 \%$ biaxial & Elastosil film & $86 \times 86 \times 25 \mathrm{~mm}^{3}$ & $100 \mathrm{~N}$ & $+3 \mathrm{~mm}$ & [73] \\
\hline Tubular & $7.5 \mathrm{kV} / 160 \mu \mathrm{m}$ & None & CF 19-2186 & $8 \times 8 \times 50 \mathrm{~mm}^{3}$ & $-20 \mathrm{~g}$ & $+14 \%$ & [42] \\
\hline Roll & $21 \mathrm{kV} / 1000 \mu \mathrm{m}$ & None & VHB 4910 & $45 \times 45 \times 40 \mathrm{~mm}^{3}$ & $-547 \mathrm{~g}$ & $+35.8 \%$ & [82] \\
\hline
\end{tabular}

${ }^{1}$ Positive if the direction of the load is opposite from the actuation, negative if it is the same. 


\section{Soft Robot Hand and Gripper}

The grasping of various-shaped objects is one of the most challenging issues in the robotics field. As a solution to this issue, DEAs attract a lot of attention from researchers. The inherent flexibility of DEA enables an intimate contact between an object and a gripper with a DEA, while making an efficient grasping configuration. Also, the lightweight and high energy density of a DEA are important characteristics in achieving a high weight ratio of gripper mass to grasping capability. Based on a simple working principle and large actuation strain of the DEA, different types of DE grippers have been developed with various configurations.

The first emergence of DE grippers was in 2007 by G. Kofod et al., based on a dielectric elastomer minimum energy structure (DEMES) [84]. An out-of-plane configuration is generated by laminating a pre-stretched DE to a flexible plastic frame [85]. The tension of the pre-stretched DE contracts its own structure and releases elastic energy. Then, a part of the released energy is stored in the flexible plastic frame, resulting in bending, as shown in Figure 7a. When voltage is applied to the DEA, the tension of the DE decreases and the whole structure is opened enough to grasp a target object. The overall gripping situation is demonstrated in Figure $7 \mathrm{~b}$.

To enhance the practicality of the DEMES gripper, a new design with multi-segment DEMES was presented in 2014 [86,87]. As shown in Figure 7c, this design consists of repetitive DEMES segments with characteristics of a high aspect ratio. The high aspect ratio enables the gripper to wrap objects of various sizes, as described in Figure 7c. However, the grasping force of this structure is not enough to hold up an object. Since the material for the DE actuator is PDMS (Sylgard 186) with an original thickness of $70 \mathrm{um}$ and a pre-stretched ratio of 1.3, it cannot generate high tension due to a low pre-stretch ratio. Although the gripping force is not sufficient, this design could be recognized as a milestone for developing DE grippers. Multi-segment DEMES with an arch-structured flexible frame was developed to achieve a higher grasping capability, as shown in Figure 7d [88]. The pre-stretched DE with the arch-structured frame can generate a higher bending moment than with a flat frame, due to the increased distance between the pre-stretched DE and neutral axis [89]. In addition, they used an acrylic elastomer, VHB 4910, as a material of the DE actuator with a high pre-stretch ratio of $5 \times$ 6 times in length and width direction, respectively. Due to the highly pre-stretched materials, the actuator can generate an enhanced output force. Thanks to the reinforced DE fingers, this gripper can lift objects that are 8-9 times heavier than the gripper's weight of $7.5 \mathrm{~g}$. Moreover, since the area of this gripper is $103 \times 40 \mathrm{~mm}$, it can hold up a practical-sized object such as a mandarin orange. As a further step, a 3D printing process was applied as a novel fabrication method of the DEMES gripper [90]. In this research, an FEM analysis of the 3D-printed DEMES gripper is investigated, while providing a systematic design strategy for a DEMES gripper.

To enhance gripping capability, stiffness modulation, as well as DE actuation, a gripper system can be adopted to. In 2015, the first approach to combine a DE gripper with a stiffness modulation element was demonstrated by Shea's group in EPFL, using a low-melting-point alloy (LMPA) as shown in Figure 8a [91]. The gripper has a unimorph configuration to generate a bending actuation and the low-melting-point alloy is embedded in a passive layer of the unimorph structure. The stiffness is modulated by a phase change of LMPA, which can be melted by Joule-heating. In the solid state of LMPA, the gripper maintains its shape and has a high stiffness to hold a target object. However, when the phase of LMPA changes to a liquid state by Joule-heating, it can alter its open/closed configuration. In a stiff state with closed configuration, the gripper with LMPA can lift an 11-g weight while the mass of the active parts of the gripper is less than $2 \mathrm{~g}$. Another study on a DE gripper with tunable stiffness is based on shape memory polymer (SMP) electrodes [92]. Carbon-infused polyurethane SMP is applied as compliant electrodes of a DEMES-structured gripper for variable stiffness modulation. The SMP electrodes have relatively high stiffness in a cold state but exhibit lower stiffness characteristics in a hot state. Therefore, the gripper is actuated in the hot state, and holds up an object in the cold state, where the gripper has higher stiffness. The results demonstrate that the DEMES gripper with SMP electrodes 
can lift a 30-g weight with a two-fingered gripper. Here, the designed finger has a weight of $0.48 \mathrm{~g}$ and an area of $71 \times 33 \mathrm{~mm}$, with $1.4 \times 1.1$ pre-stretched PDMS (Sylgard 186) material for the DE actuator.

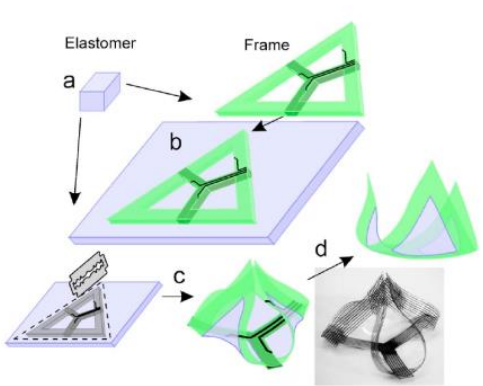

(a)

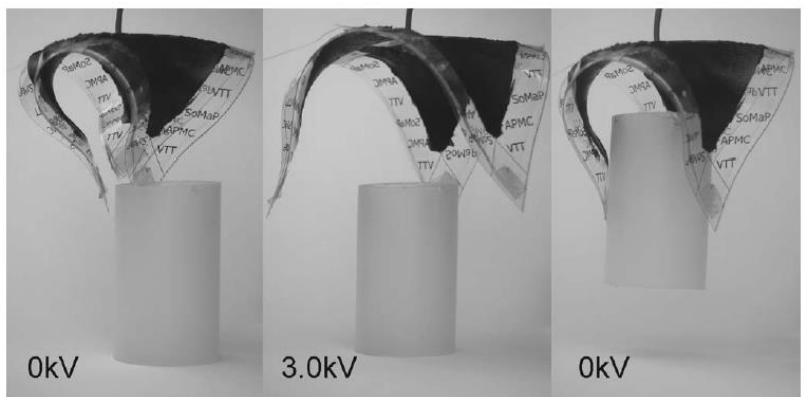

(b)

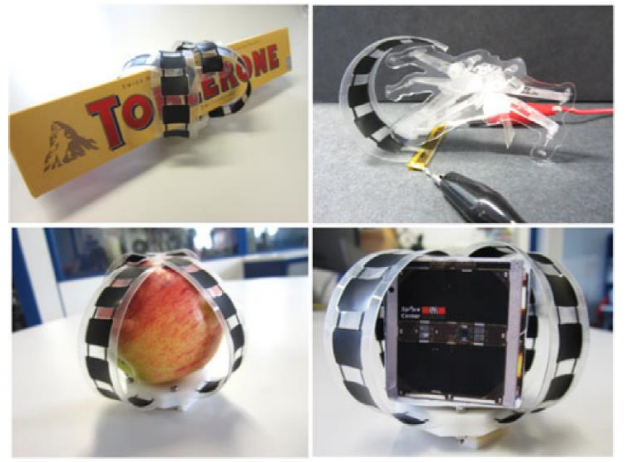

(c)

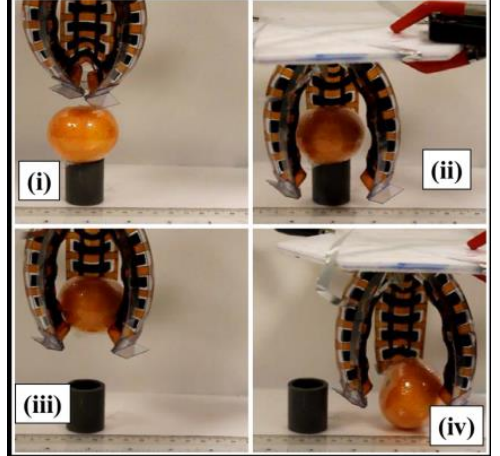

(d)

Figure 7. DE gripper based on dielectric elastomer minimum energy structure (DEMES): (a) Fabrication and working mechanism of DEMES [84]; (b) Grasping objects using DEMES gripper [84]; (c) multi-segment DEMES gripper [86]; (d) multi-segment DEMES gripper with arch flexure [88].

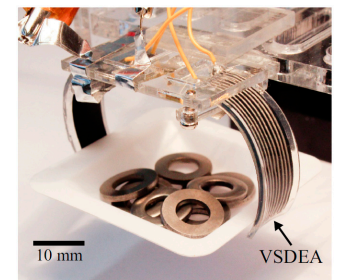

(a)

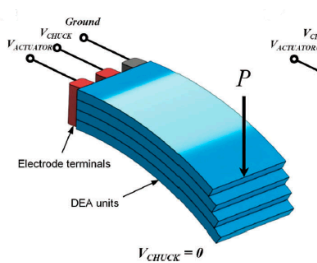

$V_{\text {CHUCK }}=0$

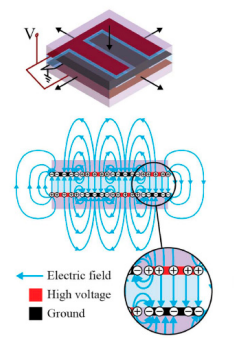

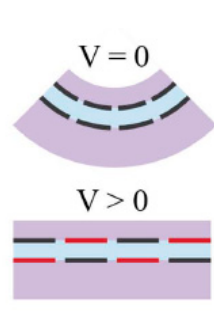

(c)

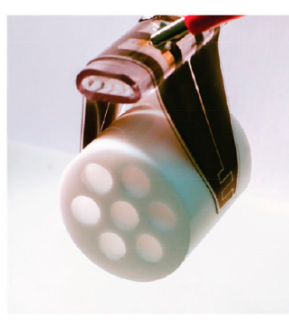

(d)

(b)
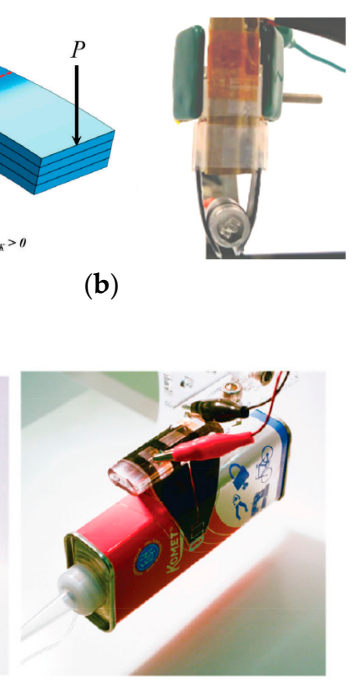

Figure 8. DE gripper with other enhancing strategy: (a) DE gripper with stiffness modulation of LMPA [91]; (b) DE gripper with stiffness modulation of electrostatic chucking [93]; (c) multipurposed electro-adhesion pattern for DE actuation [94]; (d) Grasping objects by using DE gripper with electro-adhesion [94]. 
As an alternative to Joule-heating, electrostatic chucking could be one of the working mechanisms of a variable stiffness DE gripper [93]. As shown in Figure 8b, with no voltage applied to chucking electrodes, the gripper has a lower stiffness and it can be freely bent by a DEA. However, applying a voltage to chucking electrodes generates friction between DEA units, resulting in increased stiffness. The experimental results show that a 10.2-g weight could be supported by the two-fingered gripper with six layers of chucking units in one finger. The two-finger gripper has a $0.6-\mathrm{g}$ weight and 10 $\times 20 \mathrm{~mm}$ areal dimension, when a PVDF terpolymer with a thickness of $10.6 \mathrm{um}$ was used as the DE actuator.

Other than variable stiffness methods, using adhesion with DE actuation is an effective strategy to reinforce grasping capability. A DE gripper with electro-adhesion, proposed by Shintake et al., has highly improved performance due to the intimate contact between the gripper and objects [94,95]. The principle of electroadhesion is illustrated in Figure 8c. Applying voltage to the alternative electrode pattern generates fringe electric fields, resulting in induced electric charges on the surface of target objects. The induced electric charge and voltage applied to an electrode pattern produce an attractive force between the gripper and a target object. In this research, the electro-adhesion pattern also has a role as compliant electrodes of the DEA for bending motion, as described in Figure 8c. This integrated DE gripper with electro-adhesion can generate a lifting force of $16 \mathrm{~N}$, while the gripper mass is just $1.5 \mathrm{~g}$ and the areal dimension of one finger is less than $57 \times 47 \mathrm{~mm}$, as shown in Figure $8 \mathrm{~d}$. Such extraordinary performance of the DE gripper was achieved due to the intimate contact generated by electro-adhesion.

In recent researches, novel configurations of a DE gripper have been suggested as new design strategies. One of the innovative configurations is a fiber-embedded DE gripper [96]. This design utilizes fibers to restrict DE actuation in one direction, and to induce bending in the perpendicular direction of the fibers. Therefore, a gripper with desirable bending direction, depending on target objects, can be fabricated. As another mechanism of gripping technology, DE spring-roll bending actuators, as mentioned in Section 4, are able to constitute a gripper system [97]. One bending actuator functions as a DE finger, and the DE gripper consists of three bending actuators. Recently, a new gripper structure with a cylindrical chamber was developed [98]. On the inner side of the chamber, there are four balloon-shaped DEAs. When the gripper approaches a target object, the balloon-shaped DEAs are inflated by an applied voltage. The resultant contact between DEAs and objects generates a frictional grasp to hold up the target.

Various soft DE grippers have been introduced. Yet, there remain limitations and challenges. Major disadvantages are low payload capacity and slow response time. This is due to the softness of DEAs. To overcome this issue, gripping capacity enhancing approaches were suggested, such as through stiffness modulation or adding adhesion properties. However, further research is required on increasing its payload and decreasing response time.

\section{Locomotion: Mobility Design}

Life-like motion has been a goal of robot scientists for a long time, because it is fast, agile, powerful, and can be easily adapted to the environment. DEAs are considered a prospective artificial muscle, because they have large deformation, high energy density, fast response and light weight [8]. Therefore, research has been conducted to develop a biomimetic robot system using DEAs. There are many types of locomotion robots using DEAs. For convenient classification, they can be divided into five categories: insect-like walking robots, crawling robots, flapping robots, jumping robots, and swimming robots. The locomotion robots utilize the muscle-like characteristics of DEAs. Using these characteristics, biomimetic locomotion robots aim for compliant and adaptive locomotion, which is hard and inefficient for conventional actuator technology to achieve [8]. 


\subsection{Insect-Like Walking Robot}

The world's first polymer-actuator driven legged robot, FLEX1, was built by biomimicking a cockroach [99]. The insect-like robot has six legs. Each leg has two degrees of freedom and is actuated by a bowtie shaped DEA and a spring. For each joint, the spring acts as an antagonistic component of the actuator. The robot weighs $667 \mathrm{~g}$, and its walking speed is in the order of centimeters per hour. One characteristic of this robot is that it is operated by onboard batteries, power conversion systems, and a control board. However, the poor uniformity and degradation of the actuator result in slow locomotion, and the supporting frame reduces the power density of the actuator.

Later, FLEX2 was built by the same research group, which is shown in Figure 9a [8]. Instead of a bowtie shaped actuator, FLEX2 used a spring-rolled actuator, which shows better performance in every aspect. The speed of the robot is $3.5 \mathrm{~cm} / \mathrm{s}$, which is a huge improvement, and its lifetime increased significantly.

Using the same spring-rolled actuator, Skitter, a six-legged robot, was developed [100]. Compared to the former, this robot has only one degree of freedom for each leg. The size of the robot is $178 \mathrm{~mm}$ long and $127 \mathrm{~mm}$ wide, and exhibits a locomotion speed of $7 \mathrm{~cm} / \mathrm{s}$. In MERbot, which is shown in Figure 9b, a 2-DOF spring-rolled actuator is used [80]. Here, the robot's legs are composed of only spring-rolled DEAs, without rigid linkage. For each leg, 20 layers of acrylic film (VHB 4910) are stacked in a roll. In this robot, a speed of $13.6 \mathrm{~cm} / \mathrm{s}$ is obtained at $7 \mathrm{~Hz}$.

A quadruped robot driven by a multi-stack DEA was created in 2014 [62]. This robot adopted a slider-crank mechanism to perform rotational movement at each joint. A multi-stack DEA works as a slider in the mechanism. Later, S-Hex 1 was introduced using a double cone DEA from the same research group [101]. The actuator module consists of two cone-shaped DE elastomers. For the DE elastomer, acrylonitrile-butadiene rubber (NBR) based elastomer is used with $160-\mu \mathrm{m}$ thickness. Two independent electrodes are patterned on both sides of the elastomer. This allows for 3-DOF movement of the actuator: $y$-translation, $z$-translation, and $x$-rotation. The robot consists of six actuator modules in a planar configuration, and one leg is attached to each actuator module's center. The entire dimensions of the robot are $191 \times 100 \times 115 \mathrm{~mm}$. Using z-translation and $\mathrm{x}$-rotation, the robot could show a cockroach-like tripod gait with a speed of $4 \mathrm{~mm} / \mathrm{s}$. As shown in Figure 9c, S-Hex2, which is an enhanced version of S-Hex1, is built using a 5-DOF actuator module [102]. In this robot, Silicone material (Elastosil P7670, Nusil CF2-2186 mixed with a 4:1 weight ratio) is used as the DE elastomer for increasing the tearing strength. By attaching the leg to both sides of the actuator module, the robot could walk by using only three actuator modules with a tripod gait. The robot's dimensions are $150 \times$ $54 \times 55 \mathrm{~mm}$, and a speed of $52 \mathrm{~mm} / \mathrm{s}$ is obtained at $7 \mathrm{~Hz}$, which is about 0.35 body-length per second.

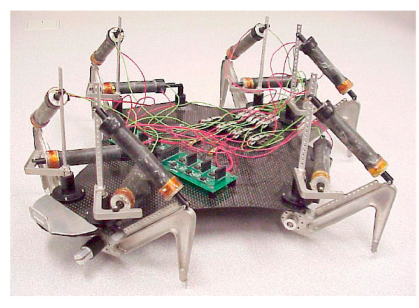

(a)

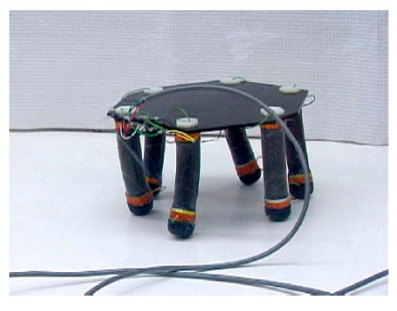

(b)

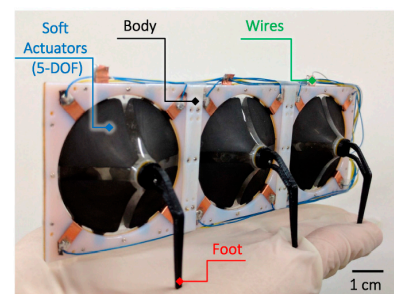

(c)

Figure 9. Insect-like waling robots which are driven by DEAs: (a) FLEX2 [8]; (b) MERbot [80]; (c) S-Hex2 [102].

\subsection{Worm-Like Crawling Robot}

The artificial annelid robot was built by using the bulging actuation of a diaphragm shaped DEA [103]. The robot was constructed by serially connecting actuator modules. Each actuator module has six diaphragm DEAs on both sides. Each diaphragm DEA is composed of 12 layers of DE film (Silicone KE441) and is $0.75 \mathrm{~mm}$ in total thickness and $5.1 \mathrm{~mm}$ in diameter. The actuator module pushes 
the neighboring module when voltage is applied. Based on the configuration of the actuator module, each sector has three DOF: up/down translational motion and two rotational motions. The dimension of the robot is $20 \mathrm{~mm}$ in diameter and $45 \mathrm{~mm}$ in length, and a $2.5 \mathrm{~mm} / \mathrm{s}$ speed is measured at $10 \mathrm{~Hz}$.

An inchworm robot was fabricated to test a unimorph DEA with embedded fiber [104]. In this robot, nylon fiber is used between two layers of acrylic film (VHB F9473PC) to constrain the bending motion of the unimorph DEA. The robot consists of a head, body, and tail. The inchworm-like contractile motion is induced in the body part which contains a $20 \mathrm{~mm}$ width and $30 \mathrm{~mm}$ length of carbon-based electrode, and anisotropic friction occurs at the head and tail part using weight and sharp tips, respectively. Using this mechanism, a $1.1 \mathrm{~mm} / \mathrm{s}$ speed is accomplished at a $0.3 \mathrm{~Hz}$ actuation rate, which is 1.3 body lengths per minute. The inchworm robot was also fabricated using electroadhesion for anisotropic friction at the front and tail part and a DEA for the bending motion of the body [105]. Compared with previous inchworm robots, electroadhesion provides for the stable locomotion of the robot. Also, all components to operate the robot are placed onboard so that an untethered and autonomous soft robot is accomplished.

In addition, a reconfigurable crawling robot was made with a double cone-shaped DEA, which is shown in Figure 10a [106]. The double cone-shaped DEA is composed of two DE membranes which are silicone elastomer (Elastosil) of $100 \mu \mathrm{m}$ thickness and $20 \mathrm{~mm}$ radius, and the two are attached to a small central disk. An alternative electric charge induces an oscillating motion of the central disk. With this oscillating motion and anisotropic friction, which is induced by a tilted bristle structure, the robot can move in two different modes: vibrational crawling and inchworm-like two-anchoring crawling. In vibrational crawling mode, the robot can move at the speed of $55 \mathrm{~mm} / \mathrm{s}$, which is 0.9 body length/s, and in two-anchoring crawling mode, the robot can carry a payload of up to $35 \%$ its body weight and achieve $0.09 \mathrm{~mm} / \mathrm{s}$ of speed.

\subsection{Flapping Robot}

For the flapping robot, a bio-inspired indirect flapping mechanism was used. In this mechanism, the actuator makes reciprocal motion between the thorax roof and bottom, which induces the flapping motion of wings. In 2002, a biomimetic thorax-type flapping robot was built and tested [8]. In this robot, a stacked DEA is connected to the upper and bottom plates. Other flapping micro air vehicles using the same mechanism were proposed with folded DEA and rolled DEA [107]. Folded DEA with a dimension of $32 \mathrm{~mm}$ height and $25 \mathrm{~mm}$ width shows $0.2 \mathrm{~mm}$ axial contraction, which induces three-degree wing strokes. On the other hand, the rolled DEA which has an $11 \mathrm{~mm}$ diameter and $61 \mathrm{~mm}$ length shows five-degree wing strokes at $0.6 \mathrm{~Hz}$. The flapping robot, which adopted resonance-based movement, was fabricated using a double cone shaped DEA in 2019 [108]. The structure of the robot is shown in Figure 10b. The overall mechanism of the wing motion is accomplished using a slider-crank mechanism. The double cone DEA acts as a slider, and the crank's rotational movement induces flapping of the wings. In this work, a rapid increase in power output at resonance frequency was observed. The robot provides a peak flapping amplitude of 63 degrees at the frequency of $18 \mathrm{~Hz}$ with a double cone shape actuator which is composed of 18 layers of $40 \mu \mathrm{m}$ silicone elastomer. The strategy of utilizing resonance frequency was also used in DEA based micro-aerial vehicles (MAVs) for flights that have succeeded in taking off (real flight) [109]. In this robot, multi-layered rolled DEA is used for linear actuation and with this linear actuation, four-bar transmission makes the wings rotate. For real flights, they used a light-weight airframe and abandoned the pre-strain of DEA which normally requires rigid and heavy supporting frames. Also, the resonance frequency is utilized for maximizing the performance of flapping motion and reducing the non-linearity of the actuator. Finally, a 100-mg MAV demonstrated open-loop lift-off at the resonance frequency of $500 \mathrm{~Hz}$. 


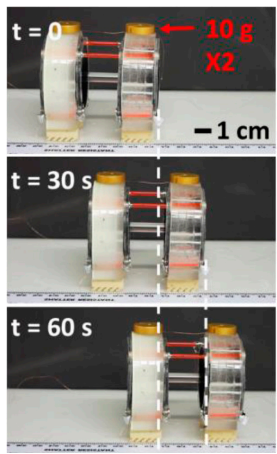

(a)

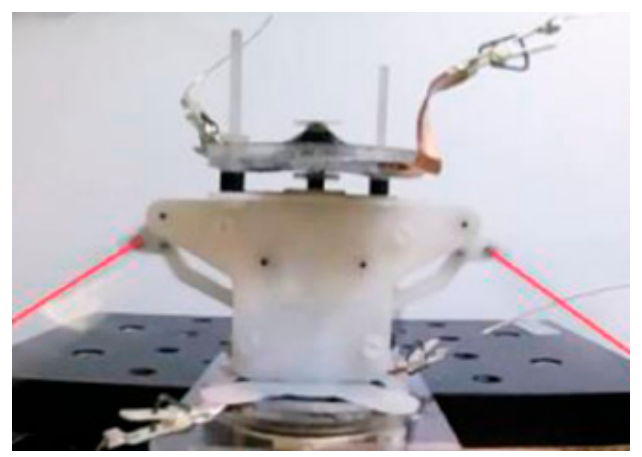

(b)

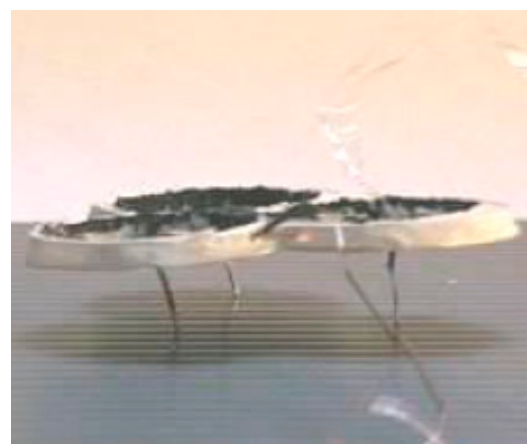

(c)

Figure 10. DEA driven crawling robot, flapping robot and jumping robot: (a) Crawling robot [106]; (b) Flapping robot [108]; (c) Jumping robot [110].

\subsection{Jumping Robot}

Jumping is also a very effective locomotion type in rough and arbitrary terrain. Several types of research were conducted to make a jumping motion using DEA. The fabrication of a jumping robot was conducted in 2004 [110]. The robot has three legs, and each leg is connected to a diaphragm shaped DEA, which is presented in Figure 10c. The dimension of the robot is $5.5 \times 5.5 \times 1.5 \mathrm{~cm}$. By changing the electric field, the actuator shows out-of-plane motion, which makes the robot jump. The robot can jump about $2 \mathrm{~cm}$, which is 1.33 times its body height.

Another type of jumping robot was made with energy storage components [111]. In this robot, a cone-shaped DEA is used as an energy pump for jumping. The DEA pumps the energy into a pair of power springs, which are made of carbon fiber strips. Then, a ratchet system prevents the release of the stored energy in the spring. After several cycles of pumping, the stored energy in the spring is released, and a jumping motion is created. This robot is $10.5 \mathrm{~cm}$ in diameter and weighs $46 \mathrm{~g}$. It can perform a $38 \mathrm{~cm}$ jump after 35 DEA pumps.

An electrical latch concept is utilized instead of a mechanical latch for the jumping motion of another robot [112]. The robot is composed of pre-stretched DE layers and a stiff layer so that the robot is initially bent. When voltage is applied to the DEA, the robot changes to a flat structure and upon discharge, the robot rapidly recovers its original bent state. Based on the fast discharge characteristic of the capacitor, the fast conversion between electrical energy and mechanical energy causes a jumping motion of the robot.

\subsection{Swimming Robot}

Recently, a swimming robot using DEA for their locomotion actuator was also suggested, which was thought of as challenging because DEAs usually use high operating voltage. Therefore, operating in the water requires a reliable insulation method. The first swimming robot using a DEA was suggested in 2016, imitating the movement of a jellyfish [113]. The robot has an air chamber inside the bell-shaped structure, which is composed of a 3D-printed cylinder and dielectric elastomer membrane (VHB 4910). So, when a voltage is applied to the DEA, the air chamber is inflated because of the expansion of the DE membrane. This actuation ejects the water inside the bell, which propel the robot while simultaneously creating buoyancy force that is greater than the weight of the robot.

Another research group fabricated a Jellyfish robot using a unimorph DEA configuration, and a fish robot with a bimorph DEA [114]. In these robots, reliable operation is guaranteed by insulating a high-voltage electrode with a silicone layer (CF19-2186) which also acts as the DE layer. A speed of 8 $\mathrm{mm} / \mathrm{s}$ is accomplished with the fish robot of $120 \mathrm{~mm}$ length, and a speed of $1.5 \mathrm{~mm} / \mathrm{s}$ is accomplished with the jellyfish robot of $800 \mathrm{~mm}$ length. The same research group also analyzed the movement of the fish robot based on the Euler-Bernoulli beam theory [115]. The fabricated fish robot is shown in Figure 11a. Using the model, the natural frequency of the robot is calculated with a fixed head 
boundary condition and compared with the experimental result. The bimorph configuration of a DEA is also used in an autonomous underwater vehicle (AUV) [116]. In this robot, all components such as a battery, power converter, and controller are included in the robot so that the robot is untethered and stand-alone.

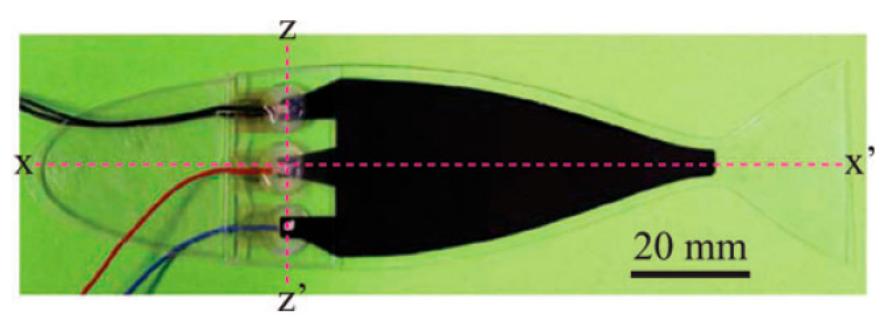

(a)

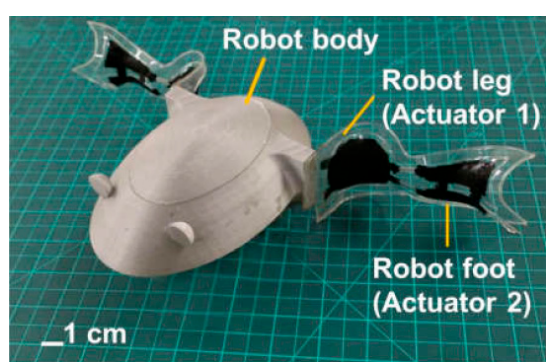

(b)

Figure 11. DEA driven swimming robot: (a) Fish robot [115]; (b) Frog robot [117].

A frog-inspired swimming robot was developed using a dielectric elastomer minimum energy structure (DEMES) [117]. For propulsion, a frog utilizes the rotation and changing surface area of their webbed feet. This movement of a frog is imitated by two segmented DEMES actuators: one segment for rotational movement and the other for the area change of the feet, which is shown as the robot leg and robot feet in Figure 11b, respectively. With these actuators, synchronously operating, maintaining, and relaxing the actuation of two segments causes the propulsion phase, glide phase, and recovery phase, respectively.

DEA based locomotion robots including insect-like walking robots, worm-like crawling robots, flapping robots, and swimming robots have been discussed in this section. However, DEA based locomotion robots lack controllability since most are controlled in open loop without sensors. As a future work, flexible sensor integrated locomotion robots with feedback scheme could be investigated for ensuring precise movement control.

\section{Wearable User Interface}

Making a wearable robot is one of the most important research issues, not only in the bio-mimicking robotics area, but also in the conventional robotics or haptics area [9]. There are four guidelines to consider when designing a wearable interface: form factor, weight, impairment, and comfort [118]. The wearable interface should be small, compact, and lightweight compared to the body part where the interface will be attached. Also, the wearable interface should not interfere with the wearer's movement, while maintaining comfort. Thus, there are many advantages for using DEAs for wearable interfaces, such as their small size, flexibility, softness, and customizability [119-131].

Portable force feedback devices for surgical simulators have been developed using DEAs. The first portable force feedback device was suggested by Zhang et al. in 2004 [119]. Chain-like actuators made from planar DEAs are attached to the backside of the index finger to give force feedback. They are made of VHB 4910 pre-stretched to $0.109 \mathrm{~mm}$ thickness as dielectric elastomer films and a 250 $\mathrm{nm}$ thickness of beaten gold as the compliant electrode. The device performs a maximum force of $0.7 \mathrm{~N}$ at $4.5 \mathrm{kV}$ under an initial pre-strain force of $4 \mathrm{~N}$, and a maximum elongation of $10.2 \%$ at 4.5 $\mathrm{kV}$ under a load of $230 \mathrm{~g}$. To enhance the output force of DEAs, multi-layered, multi-element, or multi-layer-element configurations were suggested. One way to improve output force is to use rolled DEAs [120]. The rolled DEAs have a compact structure and enhanced energy density, compared to planar DEAs. They are composed of 30-40 layers of VHB 4910, are $12 \mathrm{~mm}$ in diameter, and $45 \mathrm{~mm}$ in height. The portable force feedback device using rolled DEAs exerts a maximum force of $7.2 \mathrm{~N}$ and displays a maximum elongation of $11 \%$ at $3.5 \mathrm{kV}$.

Tactile displays using DEAs have been researched for many years. By using DEAs, the disadvantages of conventional tactile displays, such as difficulty in miniaturization and fabrication, 
low power density, high cost, and rigidity, can be overcome [121]. The first tactile display using DEAs was suggested by Choi et al. in 2008 [121]. Their system is composed of $4 \times 5$ arrays of actuators as shown in Figure 12b. To be completely soft, each actuator is composed of a polymer, especially Nusil CF-2186, with the carbon powder solution as a compliant electrode, a $2 \mathrm{~mm}$ diameter and $0.002 \mathrm{~g}$ weight. The active layer consists of eight $200 \mu \mathrm{m}$ thick layers. The actuator demonstrated an output force of over $13.6 \mathrm{mN}$ at $3.5 \mathrm{kV}$ and $0.1 \mathrm{~Hz}$, which is equivalent to a force-weight ratio of $6.8 \mathrm{~N} / \mathrm{g}$.

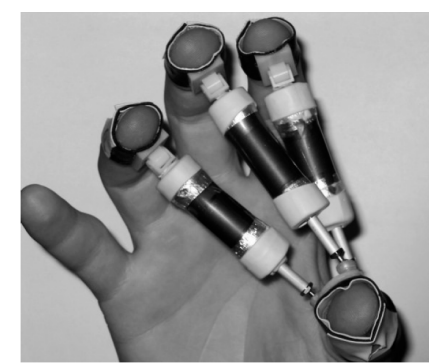

(a)

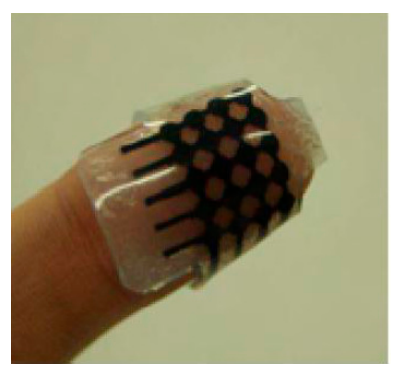

(b)

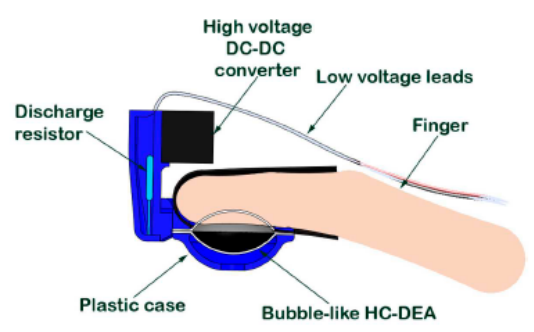

(c)

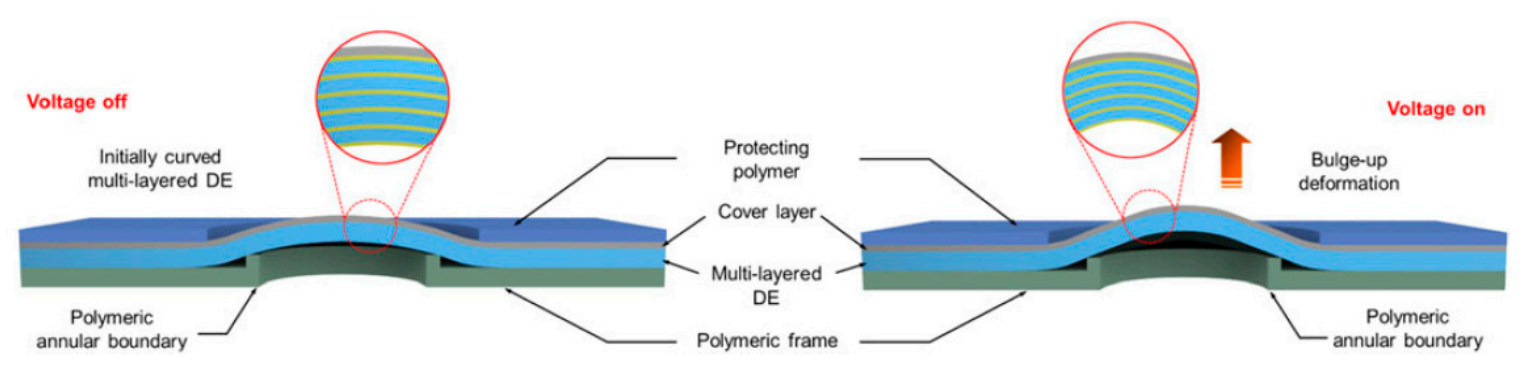

(d)

Figure 12. Wearable interfaces using DEAs: (a) force feedback system using roll DEA [120]; (b) soft tactile display using DEA [121]; (c) tactile display using HC-DEAs [124]; (d) stacked DEA with polymeric frame to maintain curvature [126].

Pre-straining DE materials could be one solution in enhancing the energy density of DEAs. However, a rigid frame is needed to maintain the pre-strain. To solve this issue, a method of embedding nylon fibers into the DEA was suggested [122]. The insertion of nylon does not deteriorate the breakdown voltage nor operation of a DEA due to the nylon's insulation property and low bending stiffness. A nylon-embedded module is attached to the forearm and conveys the shear force to the wearer. As another structure of DE tactile display, hydrostatically-coupled DEAs (HC-DEA) were suggested by Carpi et al. in 2010 [123]. The configuration of HC-DEAs for a tactile interface is shown in Figure 12c. The bubble-like form of HC-DEA is due to silicone-oil placed between the active membrane and the passive membrane. Since the active membrane is electrically connected and the passive membrane is the end-effector, the silicone oil's placement ensures electrical safety [124]. Both active and passive membranes consist of bi-axially $400 \%$ pre-stretched VHB 4910. Carbon grease is used as a compliant electrode to the active membrane. This actuator is $10 \mathrm{~mm}$ in radius and $7 \mathrm{~mm}$ in height. In this research, the maximum force is $0.6 \mathrm{~N}$ at a working voltage of $4.5 \mathrm{kV}$. To improve the output force of the HC-DEA, adopting a stacked active membrane was introduced [125]. The active membrane is made of three layers of bi-axially $300 \%$ pre-stretched VHB 4910 and carbon grease as a compliant electrode. The thickness of the passive membrane is also matched to maintain the shape of the actuator. As a result, the maximum force is measured as $0.7 \mathrm{~N}$ under the working voltage of $4.0 \mathrm{kV}$. By using stacked HC-DEAs and increasing the thickness of the passive membrane, not only was the output force enhanced, but the working voltage was also decreased.

Lower sustainability against pressurized contact is also a limitation of DEAs used as a wearable interface [126]. As shown in Figure 12d, a perforated protecting polymer is formed on the actuator to prevent the actuator from being initially pressurized. This structure can be utilized to create a 
glove-type tactile display, that can give embossed feedback at fingertips, or a patched display that can give vibro-tactile feedback to the forearm. This actuator consists of six stacks of $100 \mu \mathrm{m}$ Elastosil P7670 as dielectric elastomers, and silver nanowires (AgNWs) as compliant electrodes. The diameter of the active area is $15 \mathrm{~mm}$. The maximum force is reported as $255 \mathrm{mN}$ at $4 \mathrm{kV}$ and the resonant frequency is $191 \mathrm{~Hz}$, while the maximum vertical protrusion is $650 \mu \mathrm{m}$ under an unloading condition and at $4 \mathrm{kV}$ and $1 \mathrm{~Hz}$.

Research about the development of DE micro-actuators, which concentrate force on a localized area, was introduced in 2020 [127]. The DE micro-actuators are fabricated through photolithography, and the dimension of each micro-actuator is $200 \mu \mathrm{m} \times 7 \mathrm{~mm} \times 400 \mu \mathrm{m}$. They are made of Sylgard 184 as the dielectric elastomer and AgNWs as compliant electrodes. With these DE micro-actuators, the tactile display is organized into an array, generating more than 30 times the force of the forearm vibro-tactile displacement perception threshold at $20 \mathrm{MV} / \mathrm{m}$.

There are also other possible wearable interface applications of DEAs. An active compression bandage using DEAs was suggested. It can be taken on and off easily, fits different calf sizes, and is provided in small size modules [128]. Also, the compression magnitude of the bandage can be modulated by changing the initial pre-stretch ratio or working voltage. A hand tremor suppression using DEAs was also introduced [129]. Undesired motions by Parkinsonian tremors have faster frequency (more than $3 \mathrm{~Hz}$ ) than voluntary motion $(0 \sim 2 \mathrm{~Hz})$. By creating the motion which has that frequency of tremor, the movement can be canceled out. DEAs are attached to the wrist to reduce tremors in the flexion and extension direction. In addition to presenting these possibilities, researches on controller design and parameter design are being conducted $[130,131]$. Recently, research applying textile DEAs on a wearable interface has been conducted. In particular, replacing compliant electrodes with stretchable and conductive textiles have been investigated [132].

Wearable interfaces represent one of the recently emerging applications of DEAs. However, there are several challenges in the use of DEAs as actuators embedded into wearable devices. For example, reducing driving voltage is an issue to be solved with a high priority. High operating voltage often causes additional cost in terms of electronics as well as insulation. In addition, the insulation layers lead to output force degradation. Therefore, for low driving voltage DEA devices, we need to consider various factors including structural design, electronics cost, insulation material, as well as new DEA material with a high dielectric constant. In order to use DEA for haptic interfaces, resonant frequency needs to be considered for the efficient delivery of tactile cues to users. For example, human indentation sense is sensitive at a low frequency around $1 \sim 10 \mathrm{~Hz}$, and vibro-tactile sense is the most sensitive around $200 \mathrm{~Hz}$ [126]. So, to this purpose, we can consider a design with a specific frequency range to maximize perceived tactile sense.

\section{Optical Application with Tunablility}

Focus tunable lens technology has promising application areas including robotic systems, consumer electronics, medical imaging devices, optical detection, and many other types of optical equipment. Compared to traditional focus tunable lens structures, involving bulky motor assemblies, the adaptive focus tunable lens can tune the focal length by varying the refractive index of the optical medium or the shape of the lens surface profile. The adaptive focus tunable lens adopted various kinds of mechanisms, such as liquid-crystal (LC) based refractive index change, soft polymer deformation, liquid-droplet deformation, and electroactive polymer actuator. Recently, DEAs have been considered as attractive alternatives due to their advantages such as fast response, low power consumption, mechanical robustness, polarization-independent optical transparency, and highly reversible dynamic responses [10,133]. The adaptive focus tunable lens using DEAs can be categorized into a fluid-filled elastomeric lens [10,133-136], all-polymeric lens [137-140], and liquid droplet lens [141] based on their actuation mechanism. 


\subsection{Fluid-Filled Elastomeric Lens}

An electrically tunable optical lens using DE actuation inspired by the human eye was suggested [10]. In this work, a transparent fluid is filled between two membranes (VHB 4905, bi-axially pre-stretched $400 \%$ ), forming a symmetrical biconvex lens. In the remaining part of the membranes, a compliant electrode (carbon grease) is coated on both sides. When an electrical field is applied to compliant electrodes, the membrane contracts in thickness and expands in the planar area, as shown in Figure 13a. Thereby, the radius of the curvature of the lens changes, which causes a variation in focal length from $22.73 \mathrm{~mm}$ to $16.72 \mathrm{~mm}$, i.e., $-26.4 \%$ under the applied voltage of $3.5 \mathrm{kV}$. Like the human crystalline lens, the diameter at the rest of the tunable lens is $7.6 \mathrm{~mm}$. This tunable lens shows advantages in low power consumption, fast response, no overheating, and shock tolerance. However, since the electrode part encircles the lens part, the usable optical area is reduced. By using transparent compliant electrodes for the DEA lens, this issue can be solved [133]. The transparent DEA lens consists of a transparent liquid, one transparent passive membrane, and one transparent electroactive membrane (VHB 4910, bi-axially pre-stretched 300\%), which is coated with transparent compliant electrodes (singled walled carbon nanotube).

DE actuator deactivated

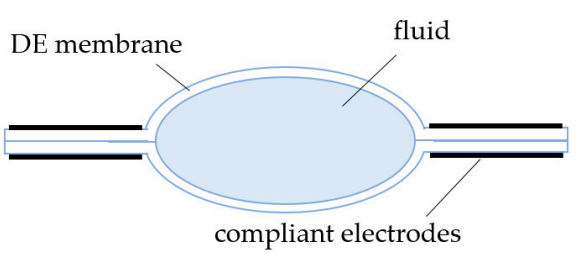

DE actuator activated

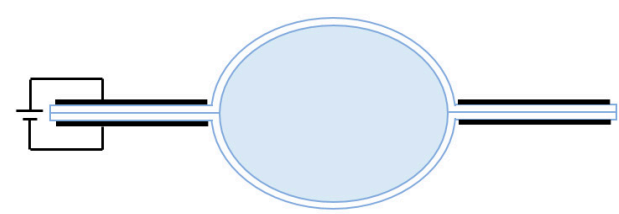

(a)

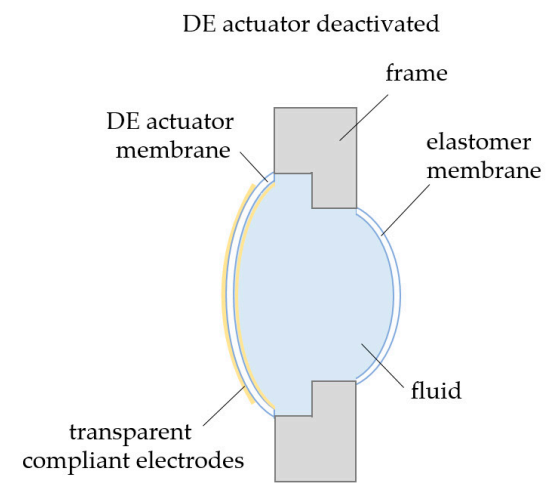

DE actuator activated

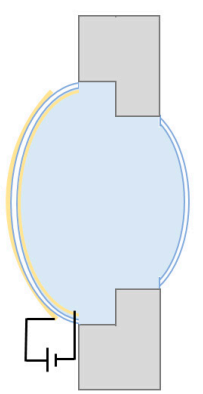

(b)

Figure 13. An operation principle of two fluid-filled elastomeric lenses using DEAs: (a) bioinspired lens; (b) transparent DEA lens.

In a similar way, the focal length of the lens varies under the voltage applied across the electroactive membrane, as shown in Figure 13b. The assembled lens has an optical transmittance of $88 \%$ at 550 $\mathrm{nm}$, while the focal length variation is observed as $103 \%$ under the operating condition of $4.9 \mathrm{kV}$, and the response time is measured to be less than one second. Although the active-lens shows a high focus tuning range, it requires a high voltage of over $4 \mathrm{kV}$. To decrease its driving voltage, a new type of fluid-filled elastomeric lens was introduced, which is driven by a concentric annular DEA [134]. This lens module has a circular reservoir and a concentric annular reservoir, which are connected by fluidic channels. The circular liquid-filled lens, with a diameter of $5 \mathrm{~mm}$, shows a large focal length tunability of $300 \%$ within $1.0 \mathrm{kV}$. Similarly, to reduce the operating voltage of the fluid-filled elastomeric lens, various approaches were suggested, such as separating the DEA diaphragm and the active-lens part [135] or using multi-stack DEAs [136]. However, a fluid-filled elastomeric lens needs 
to be improved to overcome gravitational stability for a large-aperture lens, as well as liquid leakage or diffusion problems across the membrane $[137,138]$.

\subsection{All-Polymeric Lens}

As an alternative, all-polymeric lens methods using DEAs have been suggested instead of the liquid-filled elastomeric lens. A thin film active-lens, which consists of a convex polydimethylsiloxane (PDMS) lens with a diameter of $1 \mathrm{~mm}$, a DE membrane coated with compliant electrode using silver-nanowires, and an acrylic frame, was proposed [137]. The active-lens shows optical transmittance as high as $90 \%$, and can change its focal point as high as $18.4 \%$ under $4 \mathrm{kV}$ at $1 \mathrm{~Hz}$. By adopting an all-polymer lens structure, the active lens can solve the gravity effect problem and enhanced mechanical robustness. However, the focal length change is relatively small compared to the fluid-filled elastomeric lenses. To extend the tunable range, a lens structure operated by a combination of DE membrane deformation and electro-static attraction force, was suggested [138]. The combined active lens module has two active lenses, with a convex and a concave structure, both with a diameter of $5 \mathrm{~mm}$. Each active lens consists of a DE membrane and silver nanowire electrodes, as shown in Figure 14b. With the benefits of a hybrid driving force, each active-lens can be controlled bi-directionally and shows a wide operating frequency range of 0.1-100 Hz. Furthermore, when using both DE actuation and electro-static force, the amplitude of translational displacement of the active-lens increases $230 \%$, as compared to the case of only relying on DE actuation. This increased displacement enables a wide variable focusing range.

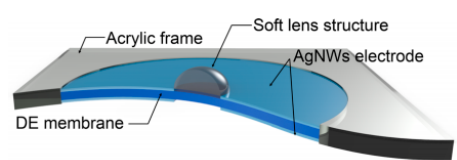

(a)

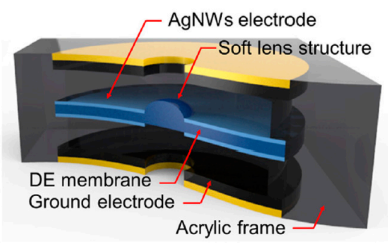

(b)

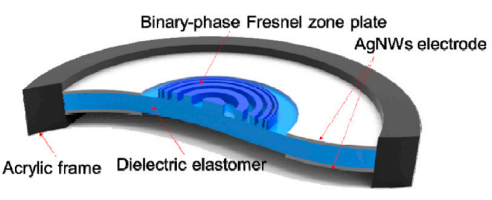

(c)

Figure 14. Structure illustration of all-polymeric lenses using DEAs: (a) a thin film active-lens [137]; (b) active-lens using hybrid driving force [138]; (c) a binary phase Fresnel lens [140].

Also, inspired by the human eye, an expansion-tunable lens module using disk-type DEA is presented by the same group [139]. A plano-convex PDMS lens, with a diameter of $3 \mathrm{~mm}$, is connected to disk-type DEA pairs, and is efficiently stretched under an applied voltage. The tunable lens shows a $65.7 \%$ change in focal length at $4.6 \mathrm{kV}$. In addition to the all-polymeric lenses, a DEA can also be adapted in a tunable binary phase Fresnel lens [140]. The tunable Fresnel lens (TFL) is composed of a thin DE membrane (Elastosil P7670, thickness:200 $\mu \mathrm{m}$ ) with binary-phase microstructure with a diameter of $10 \mathrm{~mm}$, and annular compliant electrodes made of silver nanowires. As an electric voltage is applied across the DE membrane, a compression in thickness induces in-plane deformation of the binary-phase Fresnel zone plate, and thereby, the focal length decreases. The change of the focal length is reported as $17.7 \%$ with a driving voltage at $4 \mathrm{kV}$. Since the all-polymer lens type employs fluid, they are mechanically stable, compact, and exhibit a fast response. However, due to a limitation of the DEA's maximum output force, making a large aperture tunable lens system using an all-polymer lens is still a challenge.

\subsection{Liquid Droplet Lens}

To reduce the complex fabrication process, the liquid droplet lens using a DEA has been suggested [141]. A macro size hole is drilled in the center of the DEA, and a liquid droplet which acts as a lens is filled in the hole. In the initial state, the liquid droplet maintains its biconvex shape. From the applied voltage, the DE membrane expands in the planar area, and thereby the shape of the liquid droplet, which cause a change in the focal length. The miniature liquid droplet lens has a simple 
fabrication process, and fast response time ( $540 \mathrm{~ms})$. However, the liquid droplet should be controlled in micro size and should be placed in a horizontal position for imaging due to the gravitational effect.

In this section, various types of adaptive focus tunable DEA lenses have been introduced. While DEA based tunable lenses show promising features, the controllability of the lens geometry remains a problem. Unlike hard lenses, soft lenses are prone to geometric errors on the lens surface. This may cause critical problems such as spherical aberration or image distortion. Therefore, methods to maintain and guarantee an accurate lens geometry need to be proposed to enhance the applicability and practicality of soft DEA tunable lenses.

\section{Conclusions and Perspectives}

As DEAs are emerging soft actuators, they are historically surveyed and some of the important research highlights are reviewed in this paper. The working principle and modeling of the actuator are described in the introductory sections. This review categorized and summarized various applications with DEAs as soft robot hands, locomotive robots, and wearable robots. Still, there are more potential application areas including cell manipulation in biology [142], micro-pumps and valves in micro-fluidic systems [143], active vibration isolation in mechanical structures [144], and light weight loudspeakers in acoustic devices $[145,146]$. Beyond their application to actuators, dielectric elastomers can be used as capacitive material for soft pressure and strain sensors [147]. By integrating the functional characteristics of both actuators and sensors, the self-sensing dielectric elastomer is able to be designed [148]. The development of dielectric material, compliant electrodes, and fabrication technology will continuously open new and innovative application areas for DEAs.

Although dielectric elastomer is a great candidate for artificial muscles, there are still challenges for the widespread use of DEAs. For example, a high driving voltage requires an additional power circuit [1]. This high voltage could be the most crucial issue, especially in wearable applications for safety, although it requires a very low current. As shown in Section 2, the output response of DEAs demonstrates a proportional relation with input voltage and an inverse proportional relation with their thickness. Therefore, we need to decrease the thickness of the DEA for maintaining an output under a lower driving voltage, and multiple stacking of thin films has been considered [7]. It is expected that performance of a multiple stacked actuator will be improved with the development of new fabrication methods. Low contraction force caused by material softness also needs to be improved. Contrary to the human muscle, DEAs only provide expansion force based on its working principle [1]. It usually contracts by material restoration force. Thus, there are limitations of use since there is a limitation of contraction force. New design approaches for generating high contraction force are required. Durability is also a significant issue due to the soft feature of the DEA. Since DAE is a kind of polymer, it has similar weakness to conventional polymers which are not resistive to sharp cutting, high pressure, UV (ultraviolet) light, heat and etc. Therefore, the durability of a DEA will take the same steps as new dielectric material development.

\section{Future Challenges for Practical Robotics}

Various applications of DEAs have been introduced in this paper. However, challenges still remain, such as achieving low driving voltage, high-stress output, large displacement, and enhancing the breakdown strength. First, the high voltage used in DEAs is undesirable in wearable applications and enforces the use of an external electrical component. To decrease the voltage level, the dielectric elastomer can be either multilayered or processed to thin films [149-151]. Also, increasing the material's dielectric constant (permittivity) is being researched as well $[152,153]$. Another approach is the fabrication of a high voltage controller (or an amplifier) that is small and consumes low power to eliminate the hindrance in working voltage generation [154,155].

The production of high-stress output is challenging for dielectric elastomer actuators with a simple film structure, due to their soft material properties. This limitation can be overcome by stacking [56-64] or rolling $[1,35,36,44,80-82]$ the dielectric elastomer. Its output can be amplified further by using them 
in bundles [44]. In addition, by adopting a biased spring [44,71-78] or a bi-stable structure [73] that can store elastic energy, larger stress can be output.

To achieve large displacement, artificial muscles based on dielectric elastomers are being investigated. Artificial muscles are designed to mimic human muscle characteristics. A typical human muscle displays a maximum of $40 \%$ strain in the axial direction $[13,19]$. However, such large deformation is not attained with just long linear dielectric elastomer actuators. In order to tackle this problem, research focusing on the topology of DEAs, such as stack [56,57] or conical actuators [72], needs to be performed. Another approach is the IPN (interpenetrating polymer network) method [156,157]. Since the IPN processing maintains the pre-strain induced in the dielectric elastomer, it is assumed to increase the actuator performance, while sustaining a simpler structure without an additional rigid frame.

Unexpected breakdown phenomena exist for DEAs. Such phenomena are derived from various factors, such as the material properties of DEs, the compliant electrode's properties, and surface condition. This uncertainty must be solved to guarantee a stable actuation system. As of now, methods of increasing the breakdown strength through prestretching, liquid dielectric immersion [158-160], or predicting the material's breakdown strength are being researched $[160,161]$.

Author Contributions: Working principle, characteristics and tunable optical applications, J.-H.Y.; modeling, S.M.J.; artificial muscle, J.P.; locomotion, H.K.; gripper, G.H.; wearable applications, K.H.; draft composition and supervision, K.-U.K. All authors have read and agreed to the published version of the manuscript.

Funding: This research has been supported by the R\&D Program (No.2019R1A2C2006362) of National Research Foundation (NRF), Korea (No. 01190510) and the Alchemist Project (No. 20007014) of Ministry of Trade, Industry and Energy.

Conflicts of Interest: The authors declare no conflict of interest.

\section{References}

1. Pelrine, R.E.; Kornbluh, R.D.; Joseph, J.P. Electrostriction of polymer dielectrics with compliant electrodes as a means of actuation. Sens. Actuators A 1998, 64, 77-85. [CrossRef]

2. Kornbluh, R.D.; Pelrine, R.; Pei, Q.; Heydt, R.; Stanford, S.; Oh, S.; Eckerle, J. Electroelastomers: Applications of dielectric elastomer transducers for actuation, generation, and smart structures. In Proceedings of the Smart Structures and Materials 2002: Industrial and Commercial Applications of Smart Structures Technologies, San Diego, CA, USA, 9 July 2002; pp. 245-270.

3. Borchu, P.; Pei, Q. Advances in Dielectric Elastomers for Actuators and Artificial Muscles. Macromol. Rapid Commun. 2010, 31, 10-36. [CrossRef]

4. Godaba, H.; Foo, C.C.; Zhang, Z.Q.; Khoo, B.C.; Zhu, J. Giant voltage-induced deformation of a dielectric elastomer under a constant pressure. Appl. Phys. Lett. 2014, 105, 112901. [CrossRef]

5. Michel, S.; Zhang, X.Q.; Wissler, M.; Löwe, C.; Kovacs, G. A comparison between silicone and acrylic elastomers as dielectric materials in electroactive polymer actuators. Polym. Int. 2009, 59, 391-399. [CrossRef]

6. Plante, J.; Dubowsky, S. Large-scale failure modes of dielectric elastomer actuators. Int. J. Solids Struct. 2006, 43, 7727-7751. [CrossRef]

7. Kornbluh, R. Fundamental Configurations for Dielectric Elastomer Actuators. In Dielectric Elastomers as Electromechanical Transducers: Fundamentals, Materials, Devices, Models and Applications of an Emerging Electroactive Polymer Technology, 1st ed.; Carpi, F., De Rossi, D., Kornbluh, R., Pelrine, R., Sommer-Larsen, P., Eds.; Elsevier: Oxford, UK, 2008; pp. 79-90.

8. Pelrine, R.; Kornbluh, R.D.; Pei, Q.; Stanford, S.; Oh, S.; Eckerle, J.; Full, R.J.; Rosenthal, M.A.; Meijer, K. Dielectric elastomer artificial muscle actuators: Toward biomimetic motion. In Proceedings of the Smart Structures and Materials 2002: Electroactive Polymer Actuators and Devices (EAPAD), San Diego, CA, USA, 11 July 2002; pp. 126-137.

9. Gu, G.; Zhu, J.; Zhu, L.; Zhu, X. A survey on dielectric elastomer actuators for soft robots. Bioinspir. Biomim. 2017, 12, 011003. [CrossRef] [PubMed]

10. Carpi, F.; Frediani, G.; Turco, S.; De Rossi, D. Bioinspired tunable lens with muscle-like electroactive elastomers. Adv. Funct. Mater. 2011, 21, 4152-4158. [CrossRef] 
11. Laura, J.R.; Miguel, A.L.-M.; Raquel, V. Increasing the performance of dielectric elastomer actuators: A review from the mateirals perspective. Prog. Polym. Sci. 2015, 51, 188-211.

12. Chen, Y.; Agostini, L.; Moretti, G.; Fontana, M.; Vertechy, R. Dielectric elastomer materials for large-strain actuation and energy harvesting: A comparison between styrenic rubber, natural rubber and acrylic elastomer. Smart Mater. Struct. 2019, 28, 114001. [CrossRef]

13. Madden, J.D.W.; Vandesteeg, N.A.; Anquetil, P.A.; Madden, P.G.A.; Takshi, A.; Pytel, R.Z.; Lafontaine, S.R.; Wieringa, P.A.; Hunter, I.W. Artificial muscle technology: Physical principles and naval prospects. IEEE J. Oceanic Eng. 2004, 29, 706-728. [CrossRef]

14. Kornbluh, R.D.; Pelrine, R.; Pei, Q.; Oh, S.; Joseph, J. Ultrahigh strain response of field-actuated elastomer polymers. In Proceedings of the Smart Structures and Materials 2000: Electroactive Polymer Actuators and Devices (EAPAD), Newport Beach, CA, USA, 7 June 2000; p. 387763.

15. Mirfakhrai, T.; Madden, J.D.W.; Baughman, R.H. Polymer artificial muscles. Mater. Today 2007, 10, $30-38$. [CrossRef]

16. Tan, M.W.M.; Thangavel, G.; Lee, P.S. Enhancing dynamic actuation performance of dielectric elastomer actuators by tuning viscoelastic effects with polar crosslinking. NPG Asia Mater. 2019, 11, 1-10. [CrossRef]

17. Pelrine, R.; Kornbluh, R.; Joseph, J.; Heydt, R.; Pei, Q.; Chiba, S. High-field deformation of elastomeric dielectrics for actuators. Mater. Sci. Eng. C 2000, 11, 89-100. [CrossRef]

18. Jani, J.M.; Leary, M.; Subic, A.; Gibson, M.A. A review of shape memory alloy research, applications and opportunities. Mater. Des. 2014, 56, 1078-1113. [CrossRef]

19. Jeong, J.; Yasir, I.B.; Han, J.; Park, C.H.; Bok, S.K.; Kyung, K.U. Design of Shape Memory Alloy-Based Soft Wearable Robot for Assisting Writ Motion. Appl. Sci. 2019, 9, 4025. [CrossRef]

20. Park, C.H.; Choi, K.J.; Son, Y.S. Shape Memory Alloy-Based Spring Bundle Actuator Controlled by Water Temperature. IEEE/ASME Trans. Mechatron. 2019, 24, 1798-1807. [CrossRef]

21. Li, Y.; Guo, M.; Li, Y. Recent advances in plasticized PVC gels for soft actuators and devices: A review. J. Mater. Chem. C 2019, 7, 12991-13009. [CrossRef]

22. Aziz, S.; Spinks, G.M. Torsional artificial muscles. Mater. Horiz. 2020. [CrossRef]

23. Pelrine, R.; Kornbluh, R.; Pei, Q.; Joseph, J. High-Speed Electrically Actuated Elastomers with Strain Greater Than 100\%. Science 2000, 287, 836-839. [CrossRef]

24. Carpi, F.; Chiarelli, P.; Mazzoldi, A.; Rossi, D.D. Electromechanical characterization of dielectric elastomer planar actuators: Comparative evaluation of different electrode materials and different counterloads. Sens. Actuators A 2003, 107, 85-95. [CrossRef]

25. Cho, D.Y.; Eun, K.; Choa, S.H.; Kim, H.K. Highly flexible and stretchable carbon nanotube network electrodes prepared by simple brush painting for cost-effective flexible organic solar cells. Carbon 2014, 8, 530-538. [CrossRef]

26. Liang, J.; Li, L.; Tong, K.; Ren, Z.; Hu, W.; Niu, X.; Chen, Y.; Pei, Q. Silver Nanowire Percolation Network Soldered with Graphene Oxide at Room Temperature and Its Application for Fully Stretchable Polymer Light-Emitting Diodes. ACS Nano 2014, 8, 1590-1600. [CrossRef] [PubMed]

27. Keplinger, C.; Sun, J.-Y.; Foo, K.C.C.; Rothemund, P.; Whitesides, G.M.; Suo, Z. Stretchable, Transparent, ionic Conductors. Science 2013, 341, 984-987. [CrossRef] [PubMed]

28. Tran, D.Q.; Li, J.; Xuan, F.; Xiao, T. Viscoelastic effects on the actuation performance of a dielectric elastomer actuator under different equal, un-equal biaxial pre-stretches. Mater. Res. Express 2018, 5, 065303. [CrossRef]

29. Pelrine, R.; Kornbluh, R. Electromechanical Transduction Effects in Dielectric Elastomers: Actuation, Sensing, Stiffness Modulation and Electric Energy Generation. In Dielectric Elastomers as Electromechanical Transducers: Fundamentals, Materials, Devices, Models and Applications of an Emerging Electroactive Polymer Technology, 1st ed.; Carpi, F., De Rossi, D., Kornbluh, R., Pelrine, R., Sommer-Larsen, P., Eds.; Elsevier: Oxford, UK, 2008; pp. 3-12.

30. Zhao, X.; Koh, S.J.; Suo, Z. Nonequilibrium Thermodynamics of Dielectric Elastomers. Int. J. Appl. Mech. 2011, 3, 203-217. [CrossRef]

31. Suo, Z. Theory of Dielectric Elastomers. Acta Mech. Solida Sin. 2010, 23, 449-578. [CrossRef]

32. Hong, W. Modeling viscoelastic dielectrics. J. Mech. Phys. Solids 2011, 59, 637-650. [CrossRef]

33. Zhang, J.; Chen, H.; Sheng, J.; Liu, L.; Wang, Y.; Jia, S. Dynamic performance of dissipative dielectric elastomers under alternating mechanical load. Appl. Phys. A 2014, 116, 59-67. [CrossRef] 
34. Zhang, H.; Dai, M.; Zhang, Z. Application of viscoelasticity to nonlinear analyses of circular and spherical dielectric elastomers. AIP Adv. 2019, 9, 045010. [CrossRef]

35. Zhang, J.; Chen, H.; Tang, L.; Li, B.; Sheng, J.; Liu, L. Modeling of spring roll actuators based on viscoelastic dielectric elastomers. Appl. Phys. A 2015, 119, 825-835. [CrossRef]

36. Wang, H.; Li, L.; Zhu, Y.; Yang, W. Analysis and application of a rolled dielectric elastomer actuator with two degrees of freedom. Smart Mater. Struct. 2016, 25, 125008. [CrossRef]

37. Wissler, M.; Mazza, E. Modeling and simulation of dielectric elastomer actuators. Smart Mater. Struct. 2005, 14, 1396. [CrossRef]

38. Wissler, M.; Mazza, E. Mechanical behavior of an acrylic elastomer used in dielectric elastomer actuators. Sens. Actuators A 2007, 134, 494-504. [CrossRef]

39. Li, B.; Chen, H.; Qiang, J.; Hu, S.; Zhu, Z.; Wang, Y. Effect of mechanical pre-stretch on the stabilization of dielectric elastomer actuation. J. Phys. D Appl. Phys. 2011, 44, 155301. [CrossRef]

40. Foo, C.C.; Cai, S.; Koh, S.J.; Bauer, S.; Suo, Z. Model of dissipative dielectric elastomers. J. Appl. Phys. 2012, 111, 034102.

41. Zhang, J.; Wang, Y.; McCoul, D.; Pei, Q.; Chen, H. Viscoelastic creep elimination in dielectric elastomer actuation by preprogrammed voltage. Appl. Phys. Lett. 2014, 105, 212904. [CrossRef]

42. Jung, M.Y.; Chuc, N.H.; Kim, J.W.; Koo, I.M.; Jung, K.M.; Lee, Y.K.; Nam, J.D.; Choi, H.R.; Koo, J.C. Fabrication and characterization of linear motion dielectric elastomer actuators. In Proceedings of the Smart Structures and Materials 2006: Electroactive Polymer Actuators and Devices (EAPAD), San Diego, CA, USA, 22 March 2006; p. 616824.

43. Zhang, R.; Lochmatter, P.; Kunz, A.; Kovacs, G. Spring roll dielectric elastomer actuators for a portable force feedback glove. In Proceedings of the Smart Structures and Materials 2006: Electroactive Polymer Actuators and Devices (EAPAD), San Diego, CA, USA, 22 March 2006; p. 61681T.

44. Kovacs, G.; Lochmatter, P.; Wissler, M. An arm wrestling robot driven by dielectric elastomer actuators. Smart Mater. Struct. 2007, 16, S306-S317. [CrossRef]

45. Moscardo, M.; Zhao, X.; Suo, Z.; Lapusta, Y. On designing dielectric elastomer actuators. J. Appl. Phys. 2008, 104, 093503. [CrossRef]

46. Rajamani, A.; Grissom, M.; Rahn, C.; Zhang, Q. Wound Roll Dielectric Elastomer Actuators: Fabrication, Analysis, and Experiments. IEEE-ASME Trans. Mech. 2008, 13, 117-124. [CrossRef]

47. Gu, G.; Gupta, U.; Zhu, J.; Zhu, L.; Zhu, X. Modeling of Viscoelastic Electromechanical Behavior in a Soft Dielectric Elastomer Actuator. IEEE Trans. Robot. 2017, 33, 1263-1271. [CrossRef]

48. Zhang, J.; Ru, J.; Chen, H.; Li, D.; Lu, J. Viscoelastic creep and relaxation of dielectric elastomers characterized by a Kelvin-Voigt-Maxwell model. Appl. Phys. Lett. 2017, 110, 044104. [CrossRef]

49. Zou, J.; Gu, G. Modeling the Viscoelastic Hysteresis of Dielectric Elastomer Actuators with a Modified Rate-Dependent Prandtl-Ishlinskii Model. Polymers 2018, 10, 525. [CrossRef]

50. Zou, J.; Gu, G. Feedforward Control of the Rate-Dependent Viscoelastic Hysteresis Nonlinearity in Dielectric Elastomer Actuators. IEEE Robot. Autom. Lett. 2019, 4, 2340-2347. [CrossRef]

51. Zou, J.; Gu, G. High-Precision Tracking Control of a Soft Dielectric Elastomer Actuator with Inverse Viscoelastic Hysteresis Compensation. IEEE/ASME Trans. Mech. 2019, 24, 36-44. [CrossRef]

52. Rosset, S.; Poulin, A.; Shea, H.; Anderson, I. Taming the viscoelastic creep of dielectric elastomer actuators. In Proceedings of the Electroactive Polymer Actuators and Devices (EAPAD) XXI, Denver, CO, USA, 13 March 2019; p. 1096614.

53. Wang, H.M. Viscoelastic analysis of a spring-connected dielectric elastomer actuator undergoing large inhomogeneous deformation. Int. J. Mech. Sci. 2018, 136, 17-23. [CrossRef]

54. Lv, X.; Liu, L.; Leng, J.; Liu, Y.; Cai, S. Delayed electromechanical instability of a viscoelastic dielectric elastomer balloon. Proc. R. Soc. A 2019, 475, 20190316. [CrossRef]

55. Full, R.J.; Meijer, K. Metrics of natural muscle function. In Electroactive Polymer (EAP) Actuators as Artificial Muscles: Reality, Potential, and Challenges, 2nd ed.; Bar-Cohen, Y., Ed.; SPIE Press: Bellingham, WA, USA, 2001; Chapter 3; pp. 73-89.

56. Schlaak, H.F.; Jungmann, M.; Matysek, M.; Lotz, P. Novel multilayer electrostatic solid state actuators with elastic dielectric. In Proceedings of the Smart Structures and Materials 2005: Electroactive Polymer Actuators and Devices (EAPAD), San Diego, CA, USA, 6 May 2005; pp. 121-133. 
57. Matysek, M.; Lotz, P.; Flittner, K.; Schlaak, H.F. High-precision characterization of dielectric elastomer stack actuators and their material parameters. In Proceedings of the Smart Structures and Materials 2008: Electroactive Polymer Actuators and Devices (EAPAD), San Diego, CA, USA, 10 April 2008; p. 692722.

58. Kovacs, G.; Düring, L.; Michel, S.; Terrasi, G. Stacked dielectric elastomer actuator for tensile force transmission. Sens. Actuators A 2009, 155, 299-307. [CrossRef]

59. Kovacs, G.; Düring, L. Contractive tension force stack actuator based on soft dielectric EAP. In Proceedings of the Smart Structures and Materials 2009: Electroactive Polymer Actuators and Devices (EAPAD), San Diego, CA, USA, 6 April 2009; p. 72870A.

60. Chuc, N.H.; Park, J.; Thuy, D.V.; Kim, H.S.; Koo, J.; Lee, Y.; Nam, J.; Choi, H.R. Linear artificial muscle actuator based on synthetic elastomer. In Proceedings of the Smart Structures and Materials 2007: Electroactive Polymer Actuators and Devices (EAPAD), San Diego, CA, USA, 5 April 2007; p. 65240J.

61. Chuc, N.H.; Vuong, N.H.L.; Kim, D.S.; Moon, H.P.; Koo, J.C.; Lee, Y.K.; Nam, J.-D.; Choi, H.R. Fabrication and control of rectilinear artificial muscle actuator. IEEE/ASME Trans. Mechatron. 2010, 16, 167-176. [CrossRef]

62. Nguyen, C.T.; Phung, H.; Nguyen, T.D.; Lee, C.; Kim, U.; Lee, D.; Moon, H.; Koo, J.; Nam, J.; Choi, H.R. A small biomimetic quadruped robot driven by multistacked dielectric elastomer actuators. Smart Mater. Struct. 2014, 23, 065005. [CrossRef]

63. Duduta, M.; Hajiesmaili, E.; Zhao, H.; Wood, R.J.; Clarke, D.R. Realizing the potential of dielectric elastomer artificial muscles. Proc. Natl. Acad. Sci. USA 2019, 116, 2476-2481. [CrossRef]

64. Behboodi, A.; Lee, S. Benchmarking of a Commercially Available Stacked Dielectric Elastomer as an Alternative Actuator for Rehabilitation Robotic Exoskeletons. In Proceedings of the 2019 IEEE 16th International Conference on Rehabilitation Robotics (ICORR), Toronto, ON, Canada, 24-28 June 2019; pp. 499-505.

65. Carpi, F.; Migliore, A.; Serra, G.; De Rossi, D. Helical dielectric elastomer actuators. Smart Mater. Struct. 2005, 14, 1210. [CrossRef]

66. Carpi, F.; Migliore, A.; De Rossi, D. A new contractile linear actuator made of dielectric elastomers. In Proceedings of the Smart Structures and Materials 2005: Electroactive Polymer Actuators and Devices (EAPAD), San Diego, CA, USA, 6 May 2005; pp. 64-74.

67. Carpi, F.; De Rossi, D. Contractile dielectric elastomer actuator with folded shape. In Proceedings of the Smart Structures and Materials 2006: Electroactive Polymer Actuators and Devices (EAPAD), San Diego, CA, USA, 17 March 2006; p. 61680D.

68. Carpi, F.; Salaris, C.; De Rossi, D. Folded dielectric elastomer actuators. Smart Mater. Struct. 2007, 16, S300. [CrossRef]

69. Carpi, F; De Rossi, D. Contractile folded dielectric elastomer actuators. In Proceedings of the Smart Structures and Materials 2007: Electroactive Polymer Actuators and Devices (EAPAD), San Diego, CA, USA, 4 April 2007; p. 65240D.

70. Jung, H.S.; Yang, S.Y.; Cho, K.H.; Song, M.G.; Nguyen, C.T.; Phung, H.; Kim, U.; Moon, H.; Koo, J.C.; Nam, J.-D. Design and fabrication of twisted monolithic dielectric elastomer actuator. Int. J. Control. Autom. Syst. 2017, 15, 25-35. [CrossRef]

71. Wang, H.; Zhu, J. Implementation and simulation of a cone dielectric elastomer actuator. In Proceedings of the Optomechatronic Technologies 2008, San Diego, CA, USA, 17 November 2008; p. 726607.

72. Wang, H.-M.; Zhu, J.-Y.; Ye, K.-B. Simulation, experimental evaluation and performance improvement of a cone dielectric elastomer actuator. J. Zhejiang Univ Sci. A 2009, 10, 1296-1304. [CrossRef]

73. Hau, S.; Rizzello, G.; Seelecke, S. A novel dielectric elastomer membrane actuator concept for high-force applications. Extrem. Mech. Lett. 2018, 23, 24-28. [CrossRef]

74. Choi, H.; Jung, K.M.; Kwak, J.W.; Lee, S.W.; Kim, H.; Jeon, J.W.; Do Nam, J. Multiple degree-of-freedom digital soft actuator for robotic applications. In Proceedings of the Smart Structures and Materials 2003: Electroactive Polymer Actuators and Devices (EAPAD), San Diego, CA, USA, 28 July 2003; pp. 262-271.

75. Conn, A.T.; Rossiter, J. Antagonistic dielectric elastomer actuator for biologically-inspired robotics. In Proceedings of the Smart Structures and Materials 2011: Electroactive Polymer Actuators and Devices (EAPAD), San Diego, CA, USA, 28 March 2011; p. $79761 Z$.

76. Conn, A.T.; Rossiter, J. Towards holonomic electro-elastomer actuators with six degrees of freedom. Smart Mater. Struct. 2012, 21, 035012. [CrossRef] 
77. Kwak, J.W.; Chi, H.J.; Jung, K.M.; Koo, J.C.; Jeon, J.W.; Lee, Y.; Ryew, Y.; Choi, H.R. A face robot actuated with artificial muscle based on dielectric elastomer. J. Mech. Sci. Technol. 2005, 19, 578-588. [CrossRef]

78. Cao, C.; Gao, X.; Conn, A. A compliantly coupled dielectric elastomer actuator using magnetic repulsion. Appl. Phys. Lett. 2019, 114, 011904. [CrossRef]

79. Carpi, F.; De Rossi, D. Dielectric elastomer cylindrical actuators: Electromechanical modelling and experimental evaluation. Mater. Sci. Eng. C 2004, 24, 555-562. [CrossRef]

80. Pei, Q.; Rosenthal, M.; Stanford, S.; Prahlad, H.; Pelrine, R. Multiple-degrees-of-freedom electroelastomer roll actuators. Smart Mater. Struct. 2004, 13, N86. [CrossRef]

81. Kovacs, G.M.; Ha, S.M.; Michel, S.; Pelrine, R.; Pei, Q. Study on core free rolled actuator based on soft dielectric EAP. In Proceedings of the Smart Structures and Materials 2008: Electroactive Polymer Actuators and Devices (EAPAD), San Diego, CA, USA, 10 April 2008; p. 69270X.

82. Huang, J.; Lu, T.; Zhu, J.; Clarke, D.R.; Suo, Z. Large, uni-directional actuation in dielectric elastomers achieved by fiber stiffening. Appl. Phys. Lett. 2012, 100, 211901. [CrossRef]

83. Liu, L.; Zhang, C.; Luo, M.; Chen, X.; Li, D.; Chen, H. A biologically inspired artificial muscle based on fiber-reinforced and electropneumatic dielectric elastomers. Smart Mater. Struct. 2017, 26, 085018. [CrossRef]

84. Kofod, G.; Wirges, W. Energy minimization for self-organized structure formation and actuation. Appl. Phys. Lett. 2007, 90, 081916. [CrossRef]

85. Kofod, G.; Paajanen, M.; Bauer, S. Self-organized minimum-energy structures for dielectric elastomer actuators. Appl. Phys. A 2006, 85, 141-143. [CrossRef]

86. Araromi, O.A.; Gavrilovich, I.; Shintake, J.; Rosset, S.; Richard, M.; Gass, V.; Shea, H.R. Rollable Multisegment Dielectric Elastomer Minimum Energy Structures for a Deployable Microsatellite Gripper. IEEE/ASME Trans. Mechatron. 2015, 20, 438-446. [CrossRef]

87. Araromi, O.A.; Gavrilovich, I.; Shintake, J.; Rosset, S.; Shea, H.R. Towards a deployable satellite gripper based on multisegment dielectric elastomer minimum energy structures. In Proceedings of the Smart Structures and Materials 2014: Electroactive Polymer Actuators and Devices (EAPAD), San Diego, CA, USA, 8 March 2014; p. 90562G.

88. Heng, K.; Ahmed, A.S.; Shrestha, M.; Lau, G. Strong dielectric-elastomer grippers with tension arch flexures. In Proceedings of the Smart Structures and Materials 2017: Electroactive Polymer Actuators and Devices (EAPAD), Portland, OR, USA, 17 April 2017; p. 101631Z.

89. Lau, G.; Heng, K.; Ahmed, A.S.; Shrestha, M. Dielectric elastomer fingers for versatile grasping and nimble pinching. Appl. Phys. Lett. 2017, 110, 182906. [CrossRef]

90. Zhou, F.; Zhang, M.; Cao, X.; Zhang, Z.; Chen, X.; Xizo, Y.; Liang, Y.; Wong, T.; Li, T.; Xu, Z. Fabrication and modeling of dielectric elastomer soft actuator with 3D printed thermoplastic frame. Sens. Actuators A 2019, 292, 112-120. [CrossRef]

91. Shintake, J.; Schubert, B.; Rosset, S.; Shea, H.; Floreano, D. Variable Stiffness Actuator for Soft Robotics Using Dielectric Elastomer and Low-Melting-Point Alloy. In Proceedings of the IEEE/RSJ International Conference on Intelligent Robots and Systems (IROS), Hamburg, Germany, 28 September-2 October 2015; pp. 1097-1102.

92. McCoul, D.; Rosset, S.; Besse, N.; Shea, H. Multifunctional shape memory electrodes for dielectric elastomer actuators enabling high holding force and low-voltage multisegment addressing. Smart Mater. Struct. 2016, 26, 025015. [CrossRef]

93. Imamura, H.; Kadooka, K.; Taya, M. A variable stiffness dielectric elastomer actuator based on electrostatic chucking. Soft Matter. 2017, 13, 3440-3448. [CrossRef]

94. Shintake, J.; Rosset, S.; Schubert, B.; Floreano, D.; Shea, H. Versatile Soft Grippers with Intrinsic Electroadhesion Based on Multifunctional Polymer Actuators. Adv. Mater. 2016, 28, 231-238. [CrossRef]

95. Cacucciolo, V.; Shintake, J.; Shea, H. Delicate yet strong: Characterizing the electro-adhesion lifting force with a soft gripper. In Proceedings of the IEEE International Conference on Soft Robotics (RoboSoft), Seoul, Korea, 14-18 April 2019; pp. 108-113.

96. Shian, S.; Bertoldi, K.; Clarke, D.R. Dielectric Elastomer Based “Grippers” for Soft Robotics. Adv. Mater. 2015, 27, 6814-6819. [CrossRef] [PubMed]

97. Li, J.; Liu, L.; Liu, Y.; Leng, J. Dielectric Elastomer Spring-Roll Bending Actuators: Application in Soft Robotics and Design. Soft Rob. 2019, 6, 69-81. [CrossRef] [PubMed]

98. Pourazadi, S.; Bui, H.; Menon, C. Investigation on a soft grasping gripper based on dielectric elastomer actuators. Smart Mater. Struct. 2019, 28, 035009. [CrossRef] 
99. Eckerle, O.; Stanford, S.; Marlow, J.; Schmidt, R.; Oh, S.; Low, T.; Shastri, S.V. Biologically inspired hexapedal robot using field-effect electroactive elastomer artificial muscles. In Proceedings of the SPIE 4332, Smart Structures and Materials 2001: Industrial and Commercial Applications of Smart Structures Technologies, Newport Beach, CA, USA, 14 June 2001.

100. Pei, Q.; Pelrine, R.; Stanford, S.; Kornbluh, R.D.; Rosenthal, M.S.; Meijer, K.; Full, R.J. Multifunctional electroelastomer rolls and their application for biomimetic walking robots. In Proceedings of the SPIE 4698, Smart Structures and Materials 2002: Industrial and Commercial Applications of Smart Structures Technologies, San Diego, CA, USA, 9 July 2002.

101. Nguyen, C.T.; Phung, H.; Jung, H.; Kim, U.; Nguyen, T.D.; Park, J.; Moon, H.; Koo, J.C.; Choi, H.R. Printable Monolithic Hexapod Robot Driven by Soft Actuator. In Proceedings of the 2015 IEEE International Conference on Robotics and Automation (ICRA), Seattle, WA, USA, 26-30 May 2015.

102. Nguyen, C.T.; Phung, H.; Hoang, P.T.; Nguyen, T.D.; Jung, H.; Moon, H.; Koo, J.C.; Choi, H.R. A novel bioinspired hexapod robot developed by soft dielectric elastomer actuators. In Proceedings of the 2017 IEEE/RSJ International Conference on Intelligent Robots and Systems (IROS), Vancouver, BC, Canada, 24-28 September 2017.

103. Jung, K.; Koo, J.C.; Nam, J.; Lee, Y.K.; Choi, H.R. Artificial annelid robot driven by soft actuators. Bioinspiration Biomim. 2007, 2, S42. [CrossRef] [PubMed]

104. Shian, S.; Bertoldi, K.; Clarke, D.R. Use of aligned fibers to enhance the performance of dielectric elastomer inchworm robots. In Proceedings of the SPIE 9430, Electroactive Polymer Actuators and Devices (EAPAD), San Diego, CA, USA, 1 April 2015.

105. Cao, J.; Qin, L.; Liu, J.; Ren, Q.; Foo, C.C.; Wang, H.; Lee, H.P.; Zhu, J. Untethered soft robot capable of stable locomotion using soft electrostatic actuators. Extrem. Mech. Lett. 2018, 21, 9-16. [CrossRef]

106. Cao, C.; Diteesawat, R.S.; Rossiter, J.; Conn, A.T. A Reconfigurable Crawling Robot Driven by Electroactive Artificial Muscle. In Proceedings of the 2019 2nd IEEE International Conference on Soft Robotics (RoboSoft), Seoul, Korea, 14-18 April 2019.

107. Lau, G.; Chin, Y.; La, T. Development of elastomeric flight muscles for flapping wing micro air vehicles. In Proceedings of the SPIE 10163, Electroactive Polymer Actuators and Devices (EAPAD), Portland, OR, USA, 17 April 2017.

108. Cao, C.; Burgess, S.; Conn, A.T. Toward a Dielectric Elastomer Resonator Driven Flapping Wing Micro Air Vehicle. Front. Robot. AI 2019, 5, 137. [CrossRef]

109. Chen, Y.; Zhao, H.; Mao, J.; Chirarattananon, P.; Helbling, E.F.; Hyun, N.P.; Clarke, D.R.; Wood, R.J. Controlled flight of a microrobot powered by soft artificial muscles. Nature 2019, 575, 324-329. [CrossRef]

110. Pei, Q.; Pelrine, R.; Rosenthal, M.A.; Stanford, S.; Prahlad, H.; Kornbluh, R.D. Recent progress on electroelastomer artificial muscles and their application for biomimetic robots. In Proceedings of the Volume 5385, Smart Structures and Materials 2004: Electroactive Polymer Actuators and Devices (EAPAD), San Diego, CA, USA, 27 July 2004.

111. Dubowsky, S.; Kesner, S.; Plante, J.; Boston, P. Hopping mobility concept for search and rescue robots. Ind. Robot. 2008, 35, 238-245. [CrossRef]

112. Dubuta, M.; Berlinger, F.C.J.; Nagpal, R.; Clarke, D.R.; Wood, R.J.; Temel, F.Z. Electrically-latched compliant jumping mechanism based on a dielectric elastomer actuator. Smart Mater. Struct. 2019, 28, 09LT01.

113. Godaba, H.; Li, J.; Wang, Y.; Zhu, J. A Soft Jellyfish Robot Driven by a Dielectric Elastomer Actuator. IEEE Robot. Autom. Lett. 2016, 1, 624-631. [CrossRef]

114. Shintake, J.; Shea, H.; Floreano, D. Biomimetic Underwater Robots Based on Dielectric Elastomer Actuators. In Proceedings of the 2016 IEEE/RSJ International Conference on Intelligent Robots and Systems (IROS), Daejeon, Korea, 9-14 October 2016.

115. Shintake, J.; Cacucciolo, V.; Shea, H.; Floreano, D. Soft Biomimetic Fish Robot Made of Dielectric Elastomer Actuators. Soft Robot. 2018, 5, 452-465. [CrossRef] [PubMed]

116. Berlinger, F.; Dubuta, M.; Gloria, H.; Clarke, D.; Nagpal, R.; Wood, R. A Modular Dielectric Elastomer Actuator to Drive Miniature Autonomous Underwater Vehicles. In Proceedings of the 2018 IEEE International Conference on Robotics and Automation (ICRA), Brisbane, QLD, Australia, 21-25 May 2018.

117. Tang, Y.; Qin, L.; Li, X.; Chew, C.; Zhu, J. A Frog-inspired Swimming Robot Based on Dielectric Elastomer Actuators. In Proceedings of the 2017 IEEE/RSJ International Conference on Intelligent Robots and Systems (IROS), Vancouver, BC, Canada, 24-28 September 2017. 
118. Pacchierotti, C.; Sinclair, S.; Solazzi, M.; Frisoli, A.; Hayward, V.; Prattichizzo, D. Wearable Haptic Systems for the Fingertip and the Hand: Taxonomy, Review, and Perspectives. IEEE Trans. Haptics 2017, 10, 580-600. [CrossRef] [PubMed]

119. Zhang, R.; Kunz, A.; Gabor, K.; Silvain, M.; Mazzon, A. Dielectric Elastomer Actuators for a Portable Force Feedback Device. In Proceedings of the Eurohaptics 04, Muenchen, Germany, 5-7 June 2004; pp. 300-307.

120. Zhang, R.; Kunz, A.; Lochmatter, P.; Kovacs, G. Dielectric Elastomer Spring Roll Actuators for a Portable Force Feedback Device. In Proceedings of the 2006 14th Symposium on Haptic Interfaces for Virtual Environment and Teleoperator Systems, Arlington, VA, USA, 25-26 March 2006; pp. 347-353.

121. Koo, I.K.; Jung, K.; Koo, J.; Nam, J.; Lee, Y.; Choi, H.R. Wearable Fingertip Tactile Display. In Proceedings of the SICE-ICASE International Joint Conference 2006, Busan, Korea, 18-21 October 2006; pp. 1911-1916.

122. Bolzmacher, C.; Biggs, J.; Srinivasan, M. Flexible dielectric elastomer actuators for wearable human-machine interfaces. In Proceedings of the SPIE Smart Structures + Nondestructive Evaluation 2006, San Diego, CA, USA, 16 March 2006.

123. Carpi, F.; Frediani, G.; De Rossi, D. Hydrostatically Coupled Dielectric Elastomer Actuators. IEEE-ASME Trans. Mech. 2010, 15, 308-315. [CrossRef]

124. Frediani, G.; Mazzei, D.; De Rossi, D.E.; Carpi, F. Wearable wireless tactile display for virtual interactions with soft bodies. Front. Bioeng. Biotechnol. 2014, 2, 00031. [CrossRef] [PubMed]

125. Boys, H.; Frediani, G.; Poslad, S.; Busfield, J.; Carpi, F. A dielectric elastomer actuator-based tactile display for multiple fingertip interaction with virtual soft bodies. In Proceedings of the SPIE Smart Structures + Nondestructive Evaluation 2017, Portland, OR, USA, 17 April 2017.

126. Mun, S.; Yun, S.; Nam, S.; Park, S.K.; Park, S.; Park, B.J.; Lim, J.M.; Kyung, K.U. Electro-Active Polymer Based Soft Tactile Interface for Wearable Devices. IEEE Trans. Haptics 2018, 11, 15-21. [CrossRef]

127. Yun, S.; Park, S.; Park, B.; Ryu, S.; Jeong, S.M.; Kyung, K.U. A soft and transparent visuo-haptic interface pursuing wearable devices. IEEE Trans. Ind. Electron. 2020, 67, 717-724. [CrossRef]

128. Pourazadi, S.; Ahmadi, S.; Menon, C. Towards the development of active compression bandages using dielectric elastomer actuators. Smart Mater. Struct. 2014, 23, 065007. [CrossRef]

129. Kelly, C.R.; Kauffman, J.L. Exploring dielectric elastomers as actuators for hand tremor suppression. In Proceedings of the Smart Structures and Materials 2017: Electroactive Polymer Actuators and Devices (EAPAD), Portland, OR, USA, 17 April 2017.

130. Kelly, C.R.; Kauffman, J.L. Tremor suppression controller for dielectric elastomer orthosis. In Proceedings of the Smart Structures and Materials 2018: Electroactive Polymer Actuators and Devices (EAPAD), Denver, CO, USA, 27 March 2018.

131. Kelly, C.R.; Kauffman, J.L. Necessary dielectric elastomer parameters for wearable tremor suppression. In Proceedings of the Smart Structures and Materials 2019: Electroactive Polymer Actuators and Devices (EAPAD), Denver, CO, USA, 13 March 2019.

132. Guo, J.; Xiang, C.; Helps, T.; Rossiter, J. Electroactive textile actuators for wearable and soft robots. In Proceedings of the Robosoft 2018, Livorno, Italy, 24-28 April 2018.

133. Shian, S.; Diebold, R.M.; Clarke, D.R. Tunable lenses using transparent dielectric elastomer actuators. Opt. Express 2013, 21, 8669-8676. [CrossRef]

134. Wei, K.; Zhao, Y. Electroactive liquid lens driven by an annular membrane. Opt. Lett. 2014, 39, 1318-1321. [CrossRef]

135. Keong, G.K.; La, T.G.; Shiau, L.L.; Tan, A.W.Y. Challenges of using dielectric elastomer actuators to tune liquid lens. In Proceedings of the Smart Structures and Materials 2014: Electroactive Polymer Actuators and Devices (EAPAD), San Diego, CA, USA, 8 March 2014.

136. Rasti, P.; Hous, H.; Schlaak, H.F.; Kiefer, R.; Anbarjafari, G. Dielectric elastomer stack actuator-based autofocus fluid lens. Appl. Opt. 2015, 54, 9976-9980. [CrossRef]

137. Yun, S.; Park, S.; Park, B.; Nam, S.; Park, S.K.; Kyung, K.U. A thin film active-lens with translational control for dynamically programmable optical zoom. Appl. Phys. Lett. 2015, 107, 081907. [CrossRef]

138. Yun, S.; Park, S.; Nam, S.; Park, B.; Park, S.K.; Mun, S.; Lim, J.M.; Kyung, K.U. An electro-active polymer based lens module for dynamically varying focal system. Appl. Phys. Lett. 2016, 109, 141908. [CrossRef]

139. Nam, S.; Yun, S.; Yoon, J.W.; Park, S.; Park, S.K.; Mun, S.; Park, B.; Kyung, K.U. A Robust Soft Lens for Tunable Camera Application Using Dielectric Elastomer Actuators. Soft. Robot. 2018, 5, 777-782. [CrossRef] [PubMed] 
140. Park, S.; Park, B.; Nam, S.; Yun, S.; Park, S.K.; Mun, S.; Lim, J.M.; Ryu, Y.; Song, S.H.; Kyung, K.U. Electrically tunable binary phase Fresnel lens based on a dielectric elastomer actuator. Opt. Express 2017, 25, 23801-23808. [CrossRef] [PubMed]

141. Jin, B.; Lee, J.-H.; Zhou, Z.; Zhang, G.; Lee, G.-B.; Ren, H.; Nah, C. Adaptive liquid lens driven by elastomer actuator. Opt. Eng. 2016, 55, 017107. [CrossRef]

142. Poulin, A.; Demir, C.S.; Rosset, S.; Petrova, T.V.; Shea, H. Dielectric elastomer actuator for mechanical loading of 2D cell cultures. Lab Chip 2016, 16, 3788-3794. [CrossRef] [PubMed]

143. Ghazali, F.A.M.; Mah, C.K.; AbuZaiter, A.; Chee, P.S.; Ali, M.S.M. Soft dielectric elastomer actuator micropump. Sens. Actuators A 2017, 263, 276-284. [CrossRef]

144. Sarban, R.; Jones, R.W.; Mace, B.R.; Rustighi, E. A tubular dielectric elastomer actuator: Fabrication, characterization and active vibration isolation. Mech. Syst. Signal Process. 2011, 25, 2879-2891. [CrossRef]

145. Heydt, R.; Kornbluh, R.; Eckerle, J.; Pelrine, R. Sound radiation properties of dielectric elastomer electroactive polymer loudspeakers. In Proceedings of the SPIE Smart Structures + Nondestructive Evaluation 2006, San Diego, CA, USA, 22 March 2006.

146. Hosoya, N.; Baba, S.; Maeda, S. Hemispherical breathing mode speaker using a dielectric elastomer actuator. J. Acoust. Soc. Am. 2015, 138, EL424-El428. [CrossRef]

147. Zhang, H.; Wang, M.Y. Multi-axis soft sensors based on dielectric elastomer. Soft Robot. 2016, 3, 3-12. [CrossRef]

148. Jung, K.; Kim, K.J.; Choi, H.R. A self-sensing dielectric elastomer actuator. Sens. Actuators A Phys. 2008, 143, 343-351. [CrossRef]

149. Schlaak, H.F.; Matysek, M.; Lotz, P. Fabrication and application of miniaturized dielectric elastomer stack actuators. IEEE/ASME Trans. Mechatron. 2010, 16, 58-66.

150. Clarke, D.R.; Wood, R.J.; Duduta, M. Multilayer dielectric elastomers for fast, programmable actuation without prestretch. Adv. Mater. 2016, 28, 8058-8063.

151. Shea, H.R.; Rosset, S.; Poulin, A. Printing low-voltage dielectric elastomer actuators. Appl. Phys. Lett. 2015, 107, 244104.

152. Madsen, F.B.; Yu, L.; Daugaard, A.E.; Hvilsted, S.; Skov, A.L. Silicone elastomers with high dielectric permittivity and high dielectric breakdown strength based on dipolar copolymers. Polymer 2014, 55, 6212-6219. [CrossRef]

153. Caspari, P.; Dünki, S.J.; Nüesch, F.A.; Opris, D.M. Dielectric elastomer actuators with increased dielectric permittivity and low leakage current capable of suppressing electromechanical instability. J. Mater. Chem. C 2018, 6, 2043-2053. [CrossRef]

154. Landgraf, M.; Zorell, U.; Wetzel, T.; Reitelshöfer, S.; Yoo, I.S.; Franke, J. Dielectric elastomer actuators as self-sensing devices: A new method of superimposing actuating and sensing signals. In Proceedings of the Smart Structures and Materials 2015: Electroactive Polymer Actuators and Devices (EAPAD), San Diego, CA, USA, 1 April 2015; p. 943014.

155. Lenz, S.; Holz, B.; Hau, S.; Seelecke, S. Development of a high voltage source for dielectric elastomer actuators (DEA). In Proceedings of the ACTUATOR 2018; 16th International Conference on New Actuators, Bremen, Germany, 25 June 2018; pp. 196-199.

156. Ha, S.M.; Yuan, W.; Pei, Q.; Pelrine, R.; Stanford, S. Interpenetrating Polymer Networks for High-Performance Electroelastomer Artificial Muscles. Adv. Mater. 2006, 18, 887-891. [CrossRef]

157. Ha, S.M.; Yuan, W.; Pei, Q.; Pelrine, R.; Stanford, S. Interpenetrating networks of elastomers exhibiting 300\% electrically-induced area strain. Smart Mater. Struct. 2007, 16, S280-S287. [CrossRef]

158. La, T.; Lau, G. Very high dielectric strength for dielectric elastomer actuators in liquid dielectric immersion. Appl. Phys. Lett. 2013, 102, 192905. [CrossRef]

159. Koh, S.J.A.; Li, T.; Zhou, J.; Zhao, X.; Hong, W.; Zhu, J.; Suo, Z. Mechanisms of large actuation strain in dielectric elastomers. J. Polym. Sci. Pol. Phys. 2011, 49, 504-515. [CrossRef] 
160. Gupta, U.; Qin, L.; Wang, Y.; Godaba, H.; Zhu, J. Soft robots based on dielectric elastomer actuators: A review. Smart Mater. Struct. 2019, 28, 103002. [CrossRef]

161. Zhou, J.; Jiang, L.; Cai, S. Predicting the electrical breakdown strength of elastomers. Extrem. Mech. Lett. 2018, 21, 9-16. [CrossRef]

(c)

(C) 2020 by the authors. Licensee MDPI, Basel, Switzerland. This article is an open access article distributed under the terms and conditions of the Creative Commons Attribution (CC BY) license (http://creativecommons.org/licenses/by/4.0/). 